\title{
Measurements of Heat of Vaporization and Heat Capac- ity of a Number of Hydrocarbons
}

\author{
By Nathan S. Osborne* and Defoe C. Ginnings
}

\begin{abstract}
Using a new calorimeter, accurate measurements have been made of the heat capacities of twelve hydrocarbons in the range $5^{\circ}$ to $45^{\circ} \mathrm{C}$, and of the heats of vaporization of fifty-nine hydrocarbons at $25^{\circ} \mathrm{C}$. These hydrocarbons, having from 5 to 10 carbon atoms per molecule, include 35 paraffins, 3 alkylcyclopentanes, 10 alkylcyclohexanes, and 11 alkylbenzenes.
\end{abstract}

\section{A Calorimeter for Measuring Heat of Vaporization and Heat Capacity}

\section{Introduction}

The design of a calorimeter is a very important factor in obtaining reliable results. In designing the present calorimeter, there were three principal considerations. First, the calorimeter shell should be made small because some of the hydrocarbons were available in relatively small amounts. Second, the measurements (especially vaporization) should be accurate to at least 0.1 percent. Third, the apparatus should permit relatively rapid measurements so that a large number of materials could be investigated. Making the calorimeter small has certain other advantages besides allowing the use of small samples of hydrocarbons. In a small calorimeter, it is possible to dispense with mechanical stirring and to distribute heat by a system of copper vanes. These vanes minimized the time required for thermal equilibrium and contributed both to accuracy and ease of operation. Another advantage of a small calorimeter is that it is possible to use metal shields to obtain isothermal surfaces for the control and evaluation of heat leak. This contributes to the accuracy of the results as heat leak is usually an important source of error.

\section{General Description of Method and Apparatus}

The principles of the method that was used with this apparatus have been described in previous

*Deceased. publications [1]. ${ }^{1}$ The method was applied previously $[2,3,4]$ to measurements on saturated water and steam from $0^{\circ}$ to $374^{\circ} \mathrm{C}$.

The apparatus consists essentially of a calorimeter in which a sample of the fluid may be so isolated that its amount, state, and energy may be accounted for. The sample or a definite part thereof may be made to pass through a rise of temperature or may be evaporated and withdrawn at a constant temperature while the accompanying gain or loss of energy is determined.

The sample, part liquid and part vapor, is enclosed in a metal calorimeter shell. An electric heater on this shell provides a means of adding measured energy to the shell and contents. An outlet tube with valve provides for filling the calorimeter or withdrawing vapor. Detachable receivers, suitable for weighing are connected to the outlet tube to hold the samples of fluid transferred.

For confining the energy, the calorimeter is well insulated from external sources of heat, whereas in operation the temperature of an enveloping shell is kept close to that of the calorimeter shell. By observing the temperature differences periodically, the small amount of heat that leaks to or from the calorimeter can be accounted for.

In the vaporization measurements, the process is virtually isothermal. Heat is supplied to evaporate a sample of liquid that is withdrawn from the calorimeter at a controlled rate, col-

1 Figures in brackets indicate the literature references at the end of this paper. 
lected by condensation, and weighed. It was shown by Osborne [1] that the heat put in per unit mass withdrawn is a characteristic quantity called gamma, $\gamma$, which is usually about equal to the latent heat of vaporization, $L$, for vaporization experiments performed below the normal boiling point. The difference between $\gamma$ and $L$ lies in the physical process. In a vaporization experiment in a calorimeter where the liquid is in equilibrium with its vapor, heat is supplied not only to vaporize the material withdrawn from the calorimeter, but also to vaporize material to fill up the space previously occupied by the material withdrawn from the calorimeter. This means that the quantity $\gamma$ is always larger than $L$ by this correction term, which is called beta, $\beta$.

That is,

$$
L=\gamma-\beta .
$$

The quantity $\beta$ has been shown to be

$$
\beta=L v /\left(v^{\prime}-v\right)=T v d p / d T,
$$

where $v$ and $v^{\prime}$ are specific volumes of saturated liquid and vapor, respectively, $T$ absolute temperature, and $d p / d T$ the vapor pressure derivative. In the present determinations $\beta$ is so small that approximate evaluation is adequate for derivation of values of $L$.

In the heat capacity experiments, the calorimeter with a sample of fluid is heated over a measured temperature range. By making some experiments with different amounts of fluid, it is possible to account for the tare heat capacity of the calorimeter, and to obtain the change of a quantity denoted by alpha, $\alpha$, which is a characteristic property of the fluid. The theory shows that the change in $\alpha$ differs from the change in enthalpy, $H$, of saturated liquid by the change in $\beta$, mentioned above. In algebraic form,

$$
\Delta H / \Delta T=\Delta \alpha / \Delta T+\Delta \beta / \Delta T .
$$

\section{Apparatus}

The essential features of the calorimeter may be explained by reference to figure 1 . The metal calorimeter shell, $C$, provided with an electric heater, $H$, is supported within an insulating space and is surrounded by a thermal guard shell or envelope, $E$, for control of heat leak. Provision is made for transfer of a fluid sample between the fluid container, $F C$, and the calorimeter, $C$, by

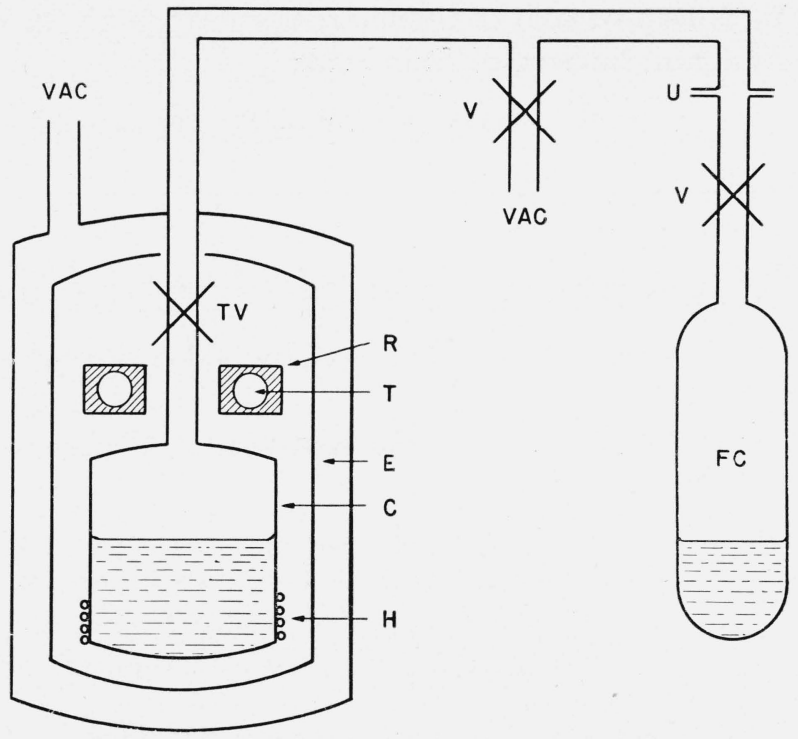

Figure 1. Schematic drawing of apparatus.

$C$, Calorimeter shell; $E$, envelope; $F C$, fluid container; $H$, calorimeter heater; $R$, reference block; $T$, resistance thermometer; $T V$, throttle valve; $U$, union; $V$, valve.

distillation through the throttle valve, $T V$. The calorimeter shell and envelope are enclosed within an outer shell with an outlet tube used for both evacuation and electric leads. The space within this outer shell, and the calorimeter and its connections may be evacuated through connections $V A C$. The copper reference block, $R$, is in a region of uniformly controlled temperature and provides a thermal connection between two platinum resistance thermometers, $T$, and the reference junctions of thermoelements used for measuring the temperatures of points on the calorimeter shell and envelope. In use, the outer shell of this calo rimeter unit was immersed in a water bath for control of surrounding temperature. The calorimeter and essential parts are shown in more detail in figure 2 .

\section{(a) Calorimeter Shell and Included Parts}

The calorimeter shell shown at $\mathrm{C}$, figure 2 is a double-walled unit. The inner shell serves as a container for the fluid sample. The outer shell, attached to the periphery of the inner shell at $A$, is a thermal shield that gives the calorimeter a nearly isothermal surface regardless of temperature gradients in the shell of the fluid container. This outer shell is made of copper $0.1 \mathrm{~mm}$ thick. The inner shell is made of brass with a cylindrical section $0.5 \mathrm{~mm}$ thick and with rounded endcaps. 


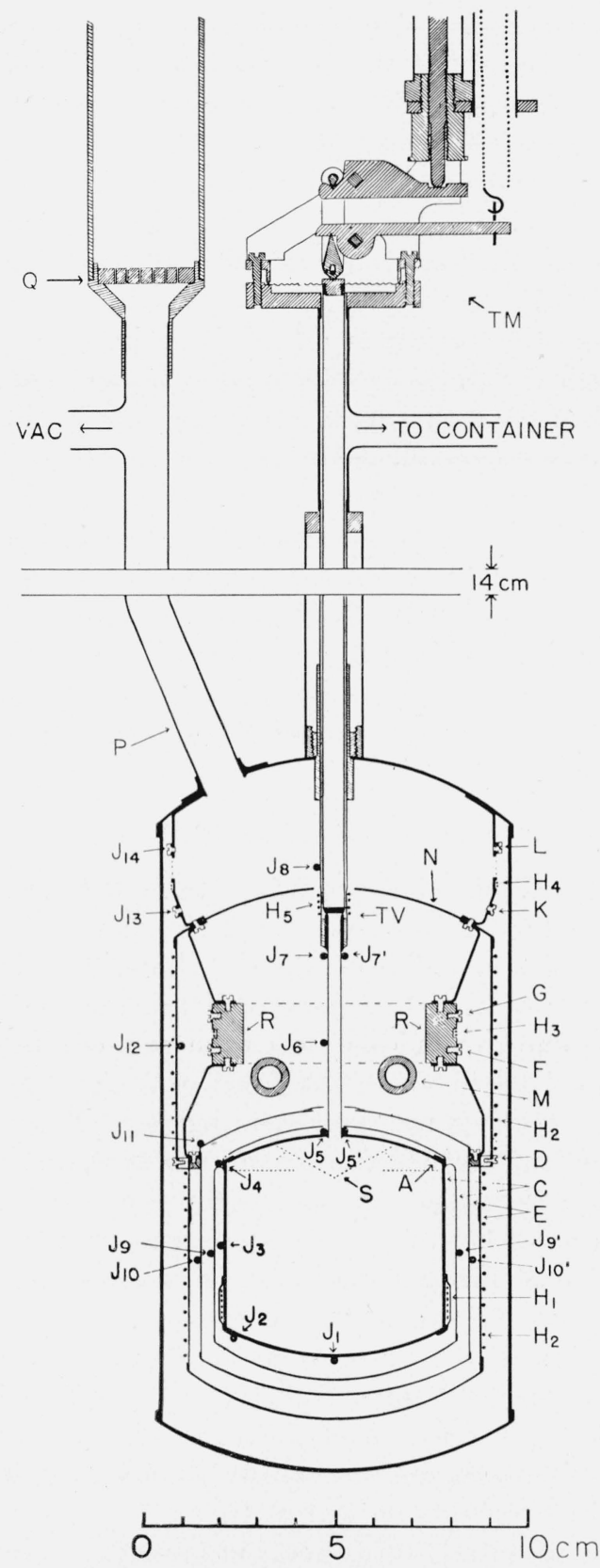

Figure 2. Scale drawing of calorimeter.

$A$, Attachment of calorimeter shell to its shield; $C$, calorimeter shell and shield; 1 ), attachment of envelope to its shield; $E$, envelope and shield; $F, G$, $K, L$, zones of thermal attachment of thermoelements; $H_{1}$, calorimeter heater; $H_{2}$, envelope heater; $H_{3}$, reference block heater; $H_{4}$, heater; $H_{5}$, throttle valve heater; $J_{1}, J_{2}$, etc., thermoelement measuring junctions; $M$, resistance thermometer receptacles; $N$, envelope deck; $P$, lead-wire duct; $Q$, seal for electrical leads; $R$, reference block; $S$, gauze baffle; $T M$, throttle valve mechanism; $T V$, throttle valve seat.

This shell is put together with soft solder, the end caps fitting into shallow recesses in the ends of the cylinder that are spun down over the caps for strength. The outer surface of the inner shell and both surfaces of the outer shell are gold-plated and polished to minimize heat transfer by radiation. Heat transfer between these shells by gaseous conduction is essentially eliminated by evacuation.

The calorimeter heater, $H_{1}$, is a $100-\mathrm{ohm}$ resistor of No. 34 constantan wire, insulated with fiber glass and wound over a strip of thin mica cemented to the brass shell by glyptal lacquer. On top of this winding is cemented another thin mica strip covered by a copper sheath, which is spun down on both sides of the winding and soldered to the brass shell. This sheath not only presses the heater element into good thermal contact with the brass shell but also conducts back to the brass shell the heat that it receives from the heater. Leads of $0.4-\mathrm{mm}$ copper wire insulated with enamel and silk are brought out from the copper sheath between mica strips.

In the interior of the calorimeter shell there was a cellular system of copper, for the purpose of promoting the rapid distribution of heat. This tends to avoid excessive thermal gradients and lag of temperature equalization. This heat distributing system consists of vertical sheets of copper ( $0.1 \mathrm{~mm}$ thick) arranged as shown in the cross section figure 3 . There are 30 sheets of tincoated copper cut to shape and bent so that, when spaced and attached by tin solder to the inner surface of the brass cylinder, they form 60 radial plates, 30 of which extend to the central void of 5 -mm diameter, and 30 more that extend to a diameter of $25 \mathrm{~mm}$. At the bottom these plates extend close to the bottom cap, whereas at the top they extend only to the level of the top joint, leaving a small open space under the top cap. With this system of plates, no part of the liquid sample in the calorimeter is more remote than about $3 \mathrm{~mm}$ from a conducting metal part.

Directly on the level top of the copper plates is a baffle $(S)$ of silver wire gauze, 100 mesh to the inch, in the form of a ring extending to the outer cylindrical wall and cut out at center to $24-\mathrm{mm}$ diameter, and spaced to allow free flow of vapor upward in the center. Another baffle of conical shape rests with vertex at center and base against the top cap at a diameter of about $3 \mathrm{~cm}$. At this perimeter, four spaces are left for vapor flow in toward the outflow tube in center of top cap. The purpose of these two baffles is to intercept any drops of liquid that might be projected directly 

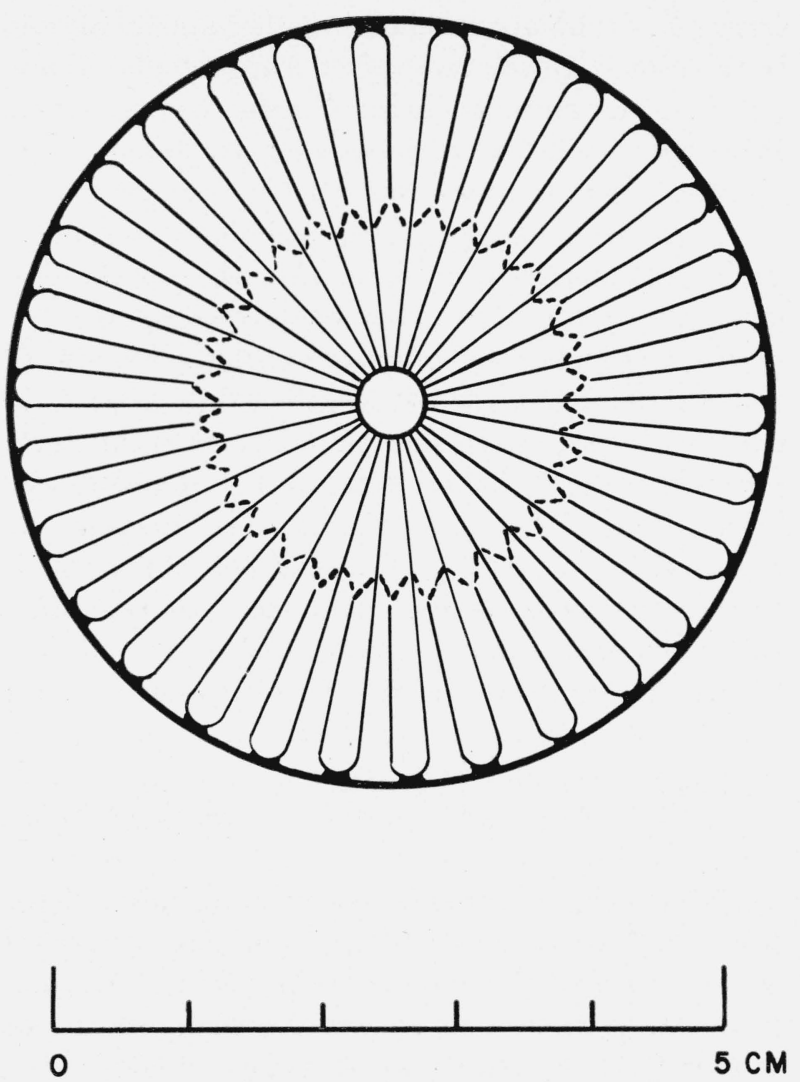

Figure 3. Calorimeter heat distributing system.

into the vapor outflow tube by active boiling, should it occur. They also probably favor the tempering of the vapor to the temperature of the top part of the calorimeter.

\section{(b) Thermal-Protecting Enclosure}

The three obvious and familiar means for avoiding the gain or loss of unmeasured heat were provided by use of a protecting enclosure for the calorimeter. These three means are thermal insulation, thermal control of envelope, and temperature-survey provision.

Thermal insulation was provided by evacuation of the space between calorimeter wall and envelope wall, and by gold plating and polishing the wall surfaces to give low emissivity. Furthermore, the unavoidable solid connections between the two elements such as electric lead wires were kept to tolerable proportions.

Thermal control of the envelope was effected by an electric heater, $\mathrm{H}_{2}$, on the outer wall of the double-walled envelope, and by survey thermoelements for observing the temperature differences.
The actual control was effected either manually by an observer of the thermoelement indications or by the automatic means to be described later. The inner guard wall of the envelope was made similar to the outer-shield wall of the calorimeter, so that residual thermal gradients in the opposed heat-leak surfaces would be alike and compensate each other.

From the periphery of the envelope at $D$, a cylindrical extension with heater $H_{2}$ and cap, $N$, provided for a thermally controlled space suitable for the reference block, $R$, and also for the outflow tube, and throttle valve, $T V$. The calorimeter shell (that part of the apparatus containing the sample of hydrocarbon) is supported by the outflow tube, which is attached to the center of the outer cap. This tube passes without contact through the envelope and through the cap, $N$, which is the upper boundary of the protecting enclosure.

\section{(c) Vapor Line and Throttle Valve}

The section of the outflow tube between the calorimeter and the seat of the throttle valve was of stainless steel ( $8 \mathrm{Ni}-18 \mathrm{Cr}$ ), having an inside diameter of $3.5 \mathrm{~mm}$ and a wall thickness of 0.25 $\mathrm{mm}$. The top of this steel tube was left thicker and was machined in the form of a circular rim, sharply beveled to about a 90 -degree angle. This beveled rim formed the seat of the throttle valve, which was closed or opened by the seating or withdrawal of the valve stem end. This consisted of a thin coating of tin on a flat silver disk normal to the axis of the valve stem.

Motion of the valve stem through the tubular stem casing of copper-nickel was controlled by a specially designed mechanism. This mechanism is the identical one previously used in apparatus for measurements on water [4].

The essential difference between the previous valve assembly and the present one is the increased length of the valve stem. In the present design, intended to be useful at subatmospheric temperatures and within an evacuated space, the length was increased to about $30 \mathrm{~cm}$ by using a section of copper-nickel tube of $5.3 \mathrm{~mm}$ outside diameter and $0.3 \mathrm{~mm}$ wall thickness, as an extension. The ends of this tubular section were formed by pressing into a triangular fluting or $Y$ shape. For the purpose of exact centering of the stem on its seat, the lower fluted section was lathe turned to 
a slip fit in the section of the tubular sleeve just above the valve seat. The end was recessed to receive the silver disk for the stem end. At the top end a brass bushing was fitted to engage the male thread of a stud extending through the diaphragm. In order to utilize the inside of the tubular stem as flow space, the tube was perforated at each end by three holes where the $Y$ section joined the circular part.

A heating coil, shown at $H_{5}$ in figure 2, was wound directly on the casing of the throttle valve to permit control of the temperature of the valve and outlet tube. The purpose of this control was to avoid error due to condensation.

The outlet tube extends vertically up from the valve and out horizontally from the diaphragm cell. From there it leads through a metal tube to a glass stopcock, beyond which a metal union provides for the attachment of one of several Pyrex-glass containers for holding a sample of fluid. A side tube permits evacuation of the vapor line. The glass containers of about $225 \mathrm{ml}$ capacity are provided with unions and stopcocks so that they can be detached and weighed for determining the amounts of samples.

\section{(d) Thermometric Installation and Other Wiring}

Platinum resistance thermometers supplemented by thermoelements were used in the control and measurement of temperatures. Two resistance thermometers placed at $M$ in the copper reference block determined a reference datum on the International Temperature Scale, from which small temperature differences to the calorimeter shell or other points were measured by means of thermoelements. Thermoelements were also used differentially for the survey of temperature distribution and for the regulation of the calorimetric processes.

The advantages of this combination of resistance thermometers and thermoelements in calorimetry have been recognized and used in this laboratory for a quarter of a century. The reliability of the modern platinum-resistance thermometer to reproduce the International Temperature Scale justifies its use to establish the reference datum of temperature. On the other hand, thermoelements are quite sufficient for supplementing resistance thermometers in the measurement of small temperature differences, because uncertainties of calibration and inhomoge- neities of wire introduce negligible errors in temperature determination. Furthermore, thermoelements have the advantages of lower heat capacity, better responsiveness, greater adaptability to limited space and to difficulty accessible points, and the possibility of multiple combinations to give integration of temperatures, more sensitivity, and measurement of temperature differences.

The use of a well-conducting, suitably shaped mass of metal as a reference block is a method of utilizing these virtues. The purpose of the reference block, besides furnishing a close thermal connection between the standard thermometer and the temperature measuring thermoelements, is also to bring all the reference junctions to a common temperature so that they may be used differentially. The increased precision and reliability gained by the use of a reference block outweighs the disadvantage of greater complexity of construction and of increased accessory equipment.

The reference block, $R$, was located in the space just above the calorimeter and envelope, where it was convenient for wiring. Here it was isolated from outer temperature differences so that its temperature was subject to precise control. This block was of copper in the form of a horizontal ring of rectangular section, to which were soldered two heavy-walled copper tubes, $M$, fitting in grooves cut in the lower face of the ring. These tubes served as resistance thermometer receptacles and were reamed to a free fit for the cylindrical platinum cases of the two resistance thermometers. A shallow groove was cut in the middle of the outer cylindrical face of the ring to receive a heating coil, $\mathrm{H}_{3}$, for temperature control. The outer cylindrical face of the ring was used for attaching reference junctions of the thermoelements and also attachments for the leads to thermoelements and resistance thermometers. These attachments, besides fixing the wires in position, were for intercepting heat conducted along the leads and will be referred to as "tie-downs".

The two platinum-resistance thermometers, one of which was used as a working standard, and the other for a calibration check, were of the four-lead potential-therminal type described by C. H. Meyers [5]. The windings were of pure platinum wound on mica cross. The wire was $0.1 \mathrm{~mm}$ in diameter and was first wound into a helix of about $0.5 \mathrm{~mm}$ diameter before being wound in the 
notched mica cross. The thermometers were encased in tubes of platinum of $6.35 \mathrm{~mm}$ outside diameter and about $0.2 \mathrm{~mm}$ thickness, which fitted closely into the receptacles in the reference block. The cases were lined with mica $0.01 \mathrm{~mm}$ thick to guard against possible electrical contact with the platinum wire.

The four lead wires were brought through holes in the shallow reentrant platinum cap, from which they were insulated by small beads of fused glass. The caps, which fitted closely into the casing, were welded to it in such a manner as to leave the outer surface clear for insertion into the receptacle, with only the leads projecting out. The opposite end of the thermometer case was spun down to a diameter of about $2.5 \mathrm{~mm}$ where a short section of glass tubing was fused on so that it could be filled with helium and sealed. The thermometers were annealed in air at about $475^{\circ} \mathrm{C}$ for about $8 \mathrm{hr}$.

The calibration was made in terms of the International Temperature Scale by using the fixed points of ice and steam and an intercomparison at $50^{\circ} \mathrm{C}$ with a primary standard resistance thermometer. The thermometers fulfilled the requirements of the International Scale and were selected from a group of four for their consistency. Each had a resistance of about $40 \mathrm{ohms}$ at the ice point.

The 16 thermoelements were all wired with leads to the outside so that each thermoelement could be used either separately or in desirable combination. The positions of the measuring junctions are indicated in figure 2. The reference junctions of the thermoelements $J_{1}$ to $J_{13}$, inclusive, are located on the reference block ( $R$ in fig. 2). The thermoelements $J_{7^{\prime}}-J_{5^{\prime}}$ and $J_{10^{\prime}}-J_{9^{\prime}}$ are differential thermoelements with junctions only where indicated. The thermoelement $J_{14}$ has its reference junction at $J_{13}$ as noted later.

The group $J_{1}$ to $J_{5}$ in series was used to measure the average temperature of the calorimeter shell relative to the reference block when the calorimeter was in equilibrium at the beginning or end of an experiment. Simultaneous readings of the resistance thermometer in the reference block completed the temperature observation.

The thermoelements $J_{6}, J_{7}$, and $J_{8}$ were located on the vapor tube along which occurs all the heat leak by conduction to and from the calorimeter shell (all the electric leads were tied thermally to this vapor tube). The combination $J_{7}$ against $J_{5}$ was used to measure this heat leak, and another duplicate combination $J_{7^{\prime}}$ against $J_{5^{\prime}}$ was used for automatic regulation of this heat flow.

The thermoelements $J_{9}$ and $J_{10}$ were located on the outer calorimeter shell and the inner envelope shell, respectively, and are used differentially to measure heat leak by radiation between these two surfaces. Heat leak by gaseous conduction and convection was eliminated by evacuation. A duplicate thermoelement combination, $J_{10^{\prime}}$ against $J_{9^{\prime}}$ was used to automatically regulate this radiant heat leak. These thermoelements were carefully located so that they indicated closely the average temperatures of their respective shells under all conditions. Temperature gradients in the shells had a negligible effect on any heat leak accounting.

The thermoelements $J_{11}, J_{12}$, and $J_{13}$ were located on the upper part of the envelope shell and were observed in order to properly distribute the heat among the heaters on the envelope shell. The thermoelement $J_{14}$ was located in thermal contact with the outer copper container and was different from the other thermoelements in that it had its reference junction at the temperature of $J_{13}$ for reading the temperature difference between $J_{14}$ and $J_{13}$. It was used in the regulation of the temperature of the bath surrounding the outer case.

The thermoelements used in this apparatus were made of No. $32(0.20-\mathrm{mm})$ Chromel P wire containing about 90 percent of $\mathrm{Ni}$ and 10 percent of Cr, and No. $34(0.16-\mathrm{mm})$ constantan wire containing about 60 percent of $\mathrm{Cu}$ and 40 percent of Ni. These wires, which gave about $60 \mu \mathrm{v}$ per degree $\mathrm{C}$ for single elements, were insulated with silk and covered with Glyptal lacquer. The junctions of these elements were made in three different ways, depending on the way the thermal contact had to be made to acquire the temperature of the surface where they were placed.

The usual type of thermoelement junction was made on a small sheet of copper, either shaped as a circular washer with a radial tag, or as a rectangular terminal. The two wires to be joined were soldered close together to the terminal in the manner described in a previous report [3]. The rectangular type terminals were used for measuring junctions on the calorimeter and its envelope, and were attached thermally by inserting them between mica insulation and cementing with lacquer under small copper clips soldered to the surface. The washer-type terminals were 
attached by clamping with screw studs and nuts between thin mica washers, either to the reference block or to the two tempering rings (yet to be described) that were installed for intercepting heat conducted from outside down the leads.

A third type of junction and attachment was used for junctions $J_{5}, J_{5^{\prime}}, J_{6}, J_{7}, J_{7^{\prime}}$ and $J_{8}$. In this type, the ends of the two wires were soldered together, and the wires reinsulated with silk, and bound and lacquered to the tube for several turns away from the junction to insure adequate thermal contact.

The thermometer leads were tied thermally to the reference block with the washer type of terminals anchoring the thermometer leads to the reference block and also at three additional zones, including the tempering rings.

Four horizontal zones of thermal attachment of thermoelements, thermometer leads and heater leads are designated in figure 2 as $F, G, K$, and $L$. Zones $F$ and $\mathrm{G}$ were located on the reference block, and had 30 screw studs for thermal "tiedown" on each zone. Zone $K$ was located on the copper tempering ring that was thermally integral with the upper cap of the envelope extension. This ring had a heater, $H_{4}$, for temperature control, and bore 40 thermal tie-downs. Zone $L$ was another tempering ring that was thermally integral with the top cap of the outer shell. This also had 40 thermal tie-downs.

Four mica struts formed the supporting attachment between ring $K$ and ring $L$, and these struts carried the entire envelope structure rigidly, with negligible heat transfer.

The reference block was carried between eight copper-nickel legs, four above and four below. These legs were $0.8 \mathrm{~mm}$ thick and $3.4 \mathrm{~mm}$ wide, and formed a near-rigid support for the envelope shell below. The envelope extension above $D$ could be lowered for access to the wiring space about the reference block. The wires leading from the reference block, zone $G$, to the tempering ring, zone $K$, passed through slots in the outer rim of the cap.

Leading from the tie-downs on the tempering ring, zone $K$, the wires passed through the gap between the two rings $K$ and $L$, and thence out through the lead-wire duct, $P$. Within this duct the wires, including thermoelements, thermometer, and heater leads were grouped into compact bundles with heater leads separate from the others to lessen danger of electric leakage. At the top of this duct the wires passed out through small holes in a lucite cap, $Q$, that was sealed with a resin lacquer, so the entire interior space could be evacuated through the side tube from the lead duct.

The system of several zones of tie-downs for the various electrical lead wires was designed to intercept heat leak along these wires to protect the thermometric elements from extraneous lead conduction effects. The small thermal conduction along the electrical leads from the calorimeter shell was accounted for by tieing them thermally to the vapor line between thermoelements $J_{7}$ and $J_{5}$, and including their conduction with the metal tube conduction as measured by $J_{7}$ against $J_{5}$.

Outside the calorimeter the leads were brought over to the observing station where specially built all-copper selector switches provided for various combinations of thermoelements for the several functions mentioned above. By manipulation of these switches, the observer could quickly shift from one combination to another with delay only for galvanometer response.

The emf's of the thermoelements were measured on a Wenner potentiometer. The errors of both the potentiometer and the thermoelements were inconsequential for this purpose.

The five thermoelements, $J_{1}$ to $J_{5}$, used to measure the temperature of the calorimeter shell, were calibrated in place by comparison with the resistance thermometer in the reference block. This procedure was first to observe the thermometer and thermoelements, when the reference block temperature was very close to that of the calorimeter. The reference block was then heated for a few seconds, while the calorimeter temperature remained virtually constant, and the observations were repeated. The change in emf of the thermoelements was thus given in terms of the temperature scale. No evidence was found that the calibration factor of any of the other similar thermoelements differed from this one, but even had they differed, the manner of use avoided any significant error due to this cause as the heat leak factors were experimentally determined, and the thermoelement readings were calibrated directly in terms of power.

The resistances of the two platinum thermometers were measured with a Mueller bridge [6] and were calibrated previous to their installation 
in the reference block. Intercomparisons of the two thermometers made at several times during the progress of the measurements showed that no significant relative change had occurred. Small changes in the thermometers would have caused only insignificant effects on the calorimetric results.

Use of a commutator with normal $(N)$ and reverse $(R)$ positions adapts the bridge for measuring the resistance thermometer. A bridge current of $0.005 \mathrm{amp}$ was used, half of which passed through the thermometer. A reversing snap switch for the bridge current served both to account for galvanometer zero drift and also to double the sensitivity.

\section{(e) Auxiliary Control Features}

One very important control feature has already been described, i. e. the vapor throttle valve. This is adjusted manually by the operator to open or shut the vapor line and to regulate the evaporation temperature.

Other control devices are used in the various heating circuits some of which are manual, some automatic, and some partly each. One of the latter type is the main switch in the calorimeter heater circuit. This is a double-pole doublethrow switch, which is thrown either way by a spring tensed by a hand lever. The switch is released for quick throw by a trigger pulled by the electric seconds signal from the standard clock. A key in the clock circuit allows the operator to choose the particular second signal to start or stop the calorimeter heating current. The heating periods are normally integral numbers of minutes.

The heating circuits for control of the temperatures of the envelope and envelope extension were divided into two entirely separate parts. One of these circuits served to supply the additional heat required during a heat capacity experiment. This heater circuit was arranged to distribute the heat according to the heat capacity of the envelope and envelope extension and was used only during a heat capacity experiment. No adjustment of the current in this heater circuit was necessary due to the use of the second heater circuit. The second heater circuit served to supply the heat lost to the surroundings from the envelope and envelope extension and was arranged to distribute heat to account for different heat transfer coefficients in different regions. This second heater circuit was operated by an automatic control at all times. By using these two heater circuits it was possible to avoid large gradients on the envelope and envelope extension during a heat capacity experiment, and still utilize automatic control.

The automatic control was actuated by the emf of thermoelements $J_{10^{\prime}}-J_{9^{\prime}}$, previously indicated. This emf in a simple potentiometer circuit, actuated a galvanometer, photoelectric cell and amplifier, which continuously regulated the heating current to control the temperature difference. The temperature gradient along the vapor tube was automatically regulated to a desired value by a similar circuit actuated by the emf of thermoelements $J_{7^{\prime}}-J_{5^{\prime}}$. Each heater is connected directly in the plate circuit of two type-25L6 electron tubes in parallel, which were in turn driven by type-38 electron tubes that were controlled by the photoelectric cell-galvanometer combination. The advantage of this system was that the control of the current in the heaters was continuous instead of on-and-off. The automatic controls regulated the temperature of the envelope and throttle at any desired temperature difference from the calorimeter even when changes occurred in the temperature of the calorimeter, such as during heat capacity experiments.

The heating coil on the reference block and the one used in the water bath are both manually controlled.

\section{(f) Measurement of Mass and Electric Energy}

A sensitive balance of a capacity of $2 \mathrm{~kg}$ with closed cabinet below in which containers, dummies, and counterpoises were suspended, was used for weighing the samples. Calibrated platinumplated brass weights were used.

A Wolff-Diesselhorst potentiometer was used for measurements of current and potential drop in the calorimeter heater. These data with time intervals furnished by a Rieffler standard clock determined the electric energy. A 0.1-ohm fourterminal resistor in series with the heater was used for the current measurement and a 1,000 to 1 ratio volt box was used for the potential drop. The potential drop was measured by two leads that join the current leads at the zone $K$ (fig. 2). The heat developed in the current leads between the calorimeter shell and the potential leads was accounted for by calculation, knowing the resist- 
ance of the leads and assuming an arbitrary calorimeter boundary near thermoelement $\boldsymbol{J}_{6}$. This correction was estimated as 0.027 percent and was believed to introduce no significant uncertainty in the results. If the calorimeter boundary had been taken at $J_{7}$ or $J_{5}$, instead of at $J_{6}$, the maximum difference in the correction would have been only 0.006 percent.

All the important electrical-measuring instruments were carefully calibrated.

\section{General Evaluation of the Calorimeter}

The calorimeter was designed mainly for measuring heats of vaporization of small amounts of hydrocarbons, and incidentally for measuring liquid heat capacities. It was found possible to make accurate measurements of the heat of vaporization with only a few grams of material. In other words, the vaporization experiments could proceed until the calorimeter was practically dry. This was made possible by the effective heat distributing system in the calorimeter and the isothermal shields on the calorimeter and envelope that made heat leak evaluation essentially independent of any temperature gradients on the calorimeter shell or on the envelope. The electronic automatic controls on the envelope and throttle temperatures, effective in all types of experiments, were a great help in the manipulation of the apparatus. The fact that vaporization experiments were made with a large number of hydrocarbons is evidence of the ease of operation of the apparatus. After a little experience, it was found possible to dry a sample of hydrocarbon, free it from air, distill it into the calorimeter, make several vaporization experiments, and empty the calorimeter, all in a normal working day.

\section{Heat of Vaporization of 59 Hydro- carbons}

\section{Introduction}

Measurements of heats of combustion of hydrocarbons are used in the determination of heats of formation of the hydrocarbons which, in turn, are used to calculate heats of reaction and equilibrium constants involving hydrocarbons. Combustion experiments usually start with the hydrocarbon in the liquid state so that knowledge of the heat of vaporization is necessary to obtain heats of formation. The calorimetric apparatus described in section I was constructed for the purpose of accurately measuring heats of vaporization of a number of samples of pure hydrocarbons that had become available.

\section{Method}

In the vaporization experiments, the measured heat was supplied electrically to evaporate liquid, while vapor was withdrawn at a rate that was controlled manually to keep a constant temperature of evaporation. According to the theory of fluid calorimetry [1], the energy added per unit mass removed as vapor, designated as gamma, $\gamma$, exceeds the latent heat of vaporization, $L$, by the quantity beta, $\beta$.

where

$$
L=\gamma-\beta,
$$

$$
\beta=L v /\left(v^{\prime}-v\right)=T v d p / d T
$$

where $T$ is absolute temperature, $p$ is the vapor pressure, and $v$ and $v^{\prime}$ are the specific volumes of liquid and vapor, respectively.

\section{Preparation of Samples}

All of the hydrocarbons used in the present investigation were obtained in 1941 and 1942 from the NBS Section on Thermochemistry and Hydrocarbons through Frederick D. Rossini. The various samples are identified as follows: $n$-Pentane, $n$-hexane, 2-methylpentane, 3-methylpentane, 2,2-dimethylbutane, $n$-heptane, 2,2-dimethylpentane, 3,3-dimethylpentane, 2,2-dimethylhexane, 2,3-dimethylhexane, 3,3-dimethylhexane, 2methyl-3-ethylpentane, 3-methyl-3-ethylpentane, 2,2,3-trimethylpentane, 2,2,4-trimethylpentane, 2,3,3-trimethylpentane, $n$-nonane, $n$-decane, methylcyclopentane, methylcyclohexane, $n$-propylcyclohexane, cis-1,2-dimethylcyclohexane, trans-1,2dimethylcyclohexane, cis-1,3-dimethylcyclohexane, trans-1,3-dimethylcyclohexane, cis-1,4-dimethylcyclohexane, trans-1,4-dimethylcyclohexane, benzene, toluene, ethylbenzene (first sample), $m$-xylene, $n$-propylbenzene, and isopropylbenzene, were samples from the same lots the purification and properties of which were later reported by Forziati, Glasgow, Willingham, and Rossini [7]:

$n$-Octane, 2-methylheptane, 3-methylheptane, 4-methylheptane, 3-ethylhexane, 2,4-dimethylhex- 
ane, 2,5-dimethylhexane, 3,4-dimethylhexane, 2,3, 4-trimethylpentane, $n$-propylcyclopentane isopropylcyclopentane, cyclohexane, ethylcyclohexane, $o$-xylene, and $p$-xylene were samples prepared by C. E. Boord and collaborators on the American Petroleum Institute Hydrocarbon Research Project (now the American Petroleum Institute Research Project 45) at the Ohio State University. 2,3-Dimethylpentane (both samples), 2,4dimethylpentane, 3-ethylpentane, 2,2,5-trimethylhexane, and 2,3,5-trimethylhexane were samples from the same lots, the purification and properties of which were later reported by Howard, Mears, Fookson, Pomerantz, and Brooks [8].

2,3-Dimethylbutane was from the material prepared by Cramer and Mulligan [9]. The second lot of ethylbenzene was from J. Timmermans [10]. 1,2,3-Trimethylbenzene, 1,2,4-trimethylbenzene, and 1,3,5-trimethylbenzene were samples from the materials whose properties were described by Mair and Schicktanz [11].

2,2,3-Trimethylbutane and hexamethylethane were samples purified by the American Petroleum Institute Research Project 6 at the National Bureau of Standards from material supplied by George Calingaert, Ethyl Corporation, Detroit, Michigan [12].

In connection with the amounts of impurity (not including water) in the samples, and the effect of such impurities on the heat of vaporization, the following points may be noted: The manner of preparation and purification of the compounds was such as to leave as impurity only those substances having boiling points and other properties near those of the given substance. The amount of such impurity was less than 0.01 mole fraction for many of the compounds, between 0.01 and 0.03 mole fraction for some, and near 0.04 mole fraction for several. It is highly improbable, however, that any of the values of the heat of vaporization will be in error by more than 1 in 1,000 because of the small differences in the values of the heat of vaporization for those close-boiling isomers that might be expected to be present in one another as impurities. For most of the compounds, it appears that the error from these impurities will not exceed 1 in 2,000 and for some the error from this source will not exceed 1 in 10,000 .

It was necessary to remove both air and a trace of water from the hydrocarbons before making calorimetric measurements on them. The air was effectively removed by distillation into a cold trap from which the air was continually removed by pumping. The trap was immersed in a solid carbon dioxide-ethanol bath so that there was negligible loss of the sample. A second distillation from the trap to the detachable container indicated that essentially all of the air had been removed.

The water was usually removed from the hydrocarbons by running the liquid hydrocarbons slowly through a tube packed with silica gel, and into the evacuated container from which the first distillation was made. Tetraethylene citrate was used as a stopcock lubricant because it was not affected by the hydrocarbon.

As traces of water were visible as ice in the cold hydrocarbon even after this drying procedure, it was necessary to measure the effectiveness of the drying. The sample of toluene sample was prepared in the usual manner and used in the calorimeter in the vaporization experiments. Upon completion of these experiments, the toluene was distilled to a bulb where the water content was measured by a method similar to that used by Aldrich [13] at this Bureau in the determination of water in gasolines. A liquid alloy of sodium-potassium was added to the hydrocarbon and agitated until all of the water had reacted. The pressure of the hydrogen evolved was measured after the hydrocarbon had been frozen with liquid air. From this pressure, and the volume and temperature of the system, the water content was calculated to be less than one part in 25,000 in the sample. This would affect the measured heat of vaporization of the toluene by less than 1 part in 5,000. It is believed that the error due to water present was never more than this amount in any of the hydrocarbons, and was usually much less.

Other experiments were performed to obtain additional evidence on the adequacy of the drying. In addition to the drying with silica gel, some experiments were made in which the water was removed by cooling the sample to solid carbon dioxide temperatures and filtering out the traces of ice with fiber glass. Other experiments were made in which the samples were dried with $\mathrm{P}_{2} \mathrm{O}_{5}$. All of these experiments indicated that the drying of the hydrocarbons with silica gel was sufficiently effective. 


\section{Experimental Procedure}

(a) Accounting for Mass, Energy, and Change in State of the Sample

The mass of fluid withdrawn as vapor enters as a direct factor in the reduction of the data, and therefore the results can be no more reliable than the determinations of these masses. Special care was taken therefore to avoid both systematic or accidental error in the weighings. For each filling, an account was kept of the amount in the calorimeter at any time and a final mass check made by completely exhausting and weighing the residual after a series of experiments.

The amount of fluid evaporated and collected by condensation was seldom less than $10 \mathrm{~g}$ in a single experiment, although occasionally when the supply was limited, smaller portions were taken.

In order that the weighings be made with suitable precision, the glass containers holding the condensed samples were given a routine treatment of preliminary conditioning. The container, holding a sample that had been collected by condensation in a cold bath of dry ice and alcohol, was warmed to the temperature of the room. The container was then wiped dry with a towel, dried further in front of a fan, and then hung in the balance case for at least 30 minutes to assume a steady temperature. Weighings were then made by substitution, estimating to $0.1 \mathrm{mg}$ by reading swings. A dummy glass container was kept in the balance case and was weighed either just before or after the sample, to eliminate errors of weighing due to accidental changes in the balance or the counterpoise. The weights were corrected for buoyancy in air.

Measured energy was supplied electrically to the calorimeter and its contents by means of the heating coil installed on the sample container as described in section I. Power was supplied by a separate storage battery of large current capacity. Potentiometer readings were made periodically for obtaining the energy added electrically, as described later.

In order to avoid a large initial change when the current was switched to the calorimeter heater at the start of an experiment, a substitute resistor, equal to the calorimeter heater resistance, was used to adjust and steady the battery output. Between experiments, the current in the substitute was adjusted to the value selected to give the desired evaporation rate in the next experiment.

The means provided for the control and evaluation of heat leak have been described in section I. In operation, there were usually small deviations from the ideal control that would have annulled heat leak. The small corrections for this remaining heat leak were evaluated with the aid of the differential thermoelements. The indicated differences were observed every minute and added algebraically to give sums in temperature-time units called "heat-leak factors." These factors, when multiplied by "heat-leak coefficients," gave the heat-leak corrections for the energy in the individual experiments. The calorimeter was designed to make the coefficients small both by construction and by evacuation of the insulating space, and the manipulation of the envelope control was such as to make the factors small.

The heat-leak coefficients were determined experimentally during the early part of the program and were checked later. This was done by separate blank experiments with no electrical heatinput to the calorimeter and with no vapor withdrawal. The temperature difference between the calorimeter and envelope was held at a large measured value for a chosen time, yielding an exaggerated heat-leak factor. The envelope heatleak coefficient was calculated from the energy change of the calorimeter and its contents, where this energy change was computed from initial and final calorimeter temperatures and the heat capacity of the calorimeter. Similarly, the tube heat-leak coefficient was determined in an experiment with an exaggerated tube heat-leak factor.

The correction for heat leak usually consisted of three parts, designated as "envelope," "tube," and "residual" heat leaks. The envelope heat leak was usually small because of the adjustment of the automatic control. The tube heat leak was purposely allowed to be larger in order to permit the temperature of the throttle and upper part of the vapor tube to run high enough to avoid condensation in the outflow tube. During the actual withdrawal of vapor, the tube heat leak was shown to be negligible, as the vapor flow controlled the temperature of the tube where it joined the calorimeter shell.

The residual heat leak was that which was not accounted for by the routine envelope and tube heat-leak determinations, because of possible devi- 
ations of the heat-leak coefficients from the values measure. This residual heat leak was accounted for by making frequent blank experiments while the calorimeter was in equilibrium between evaporation experiments. In these, both envelope and tube heat leaks were kept normal and accounted for, leaving the deviation of the energy accounting to give a rate of leak per unit of time, which if of significant amount, could be applied to the preceding experiment as a supercorrection.

The temperature of the calorimeter and contents, when in equilibrium, was measured by a resistance thermometer in conjunction with thermoelements, as previously described. The temperature change of the calorimeter and contents was thus always accurately observed in all experiments. All temperatures were finally expressed on the International Temperature Scale.

For determining either the initial or final temperature, each temperature observation consisted of simultaneous readings of the resistance thermometer and thermoelements. The five thermoelements $J_{1}-J_{5}$, in series, indicated the mean temperature of the calorimeter with respect to the reference block. Four successive temperature readings were made at half-minute intervals, from which the mean temperature was computed.

The temperature at which evaporation proceeded is of some importance, as the heat of vaporization varies with temperature. This was controlled by the operator to keep it as near as possible to the initial temperature. Thermoelement $J_{5}$ was taken as the guide for this control. Previous experience [4] together with surveys of the temperature distribution on the calorimeter shell during evaporation indicated that this point represented the best approximation to the temperature of the vapor as it left the calorimeter.

\section{(b) Description of Vaporization Experiments}

In preparation for a series of experiments on a sample, the calorimeter and vapor line were cleared of air by evacuation. The sample, prepared as previously described, was transferred from the glass container to the calorimeter by distillation. To do this, ice was packed around the calorimeter, and necessary heat was supplied to the container to evaporate the liquid. In this preliminary charging, the insulating space was filled with helium to increase the rate of heat flow from the calorimeter. For some of the samples of higher boiling points, the available pressure differential was so small that it required a long time for the transfer.

After the sample was transferred, the container was reweighed and the calorimeter was heated to the temperature of measurement, usually $25^{\circ} \mathrm{C}$, keeping the valve and tube at a temperature above that of the calorimeter to avoid condensation in the tube. Before starting the experiment, the insulating space outside the calorimeter was evacuated to provide the insulation. A weighed glass container was attached and the line evacuated to the throttle valve. The container was opened to the line and the apparatus was then ready to start the experiment.

The initial equilibrium temperature of the calorimeter and contents was observed first. At the beginning of a chosen minute the current was switched from the substitute resistor to the calorimeter heater by the automatic time-tripped switch. The throttle valve was then opened by the operator who was also observing the thermoelements. The valve was adjusted continuously so as to keep $J_{5}$ at zero. The reference block was kept at a constant temperature as shown by the resistance thermometer. The upper part of the calorimeter, which followed closely the evaporation temperature, was maintained at the initial reference block temperature by regulating the vapor flow through the valve to just balance the energy added to the calorimeter. During the evaporation period the lower part of the calorimeter in contact with the liquid became warmer by the amount of superheating necessary to conduct the heat to the surface for evaporation.

To evaluate the heat-leak factors, the differential thermoelements, $J_{9}-J_{10}$, and $J_{7}-J_{5}$, were observed at 1-minute intervals. The constancy of the reference-block temperature was frequently checked to furnish a steady zero for thermoelement $J_{5}$, used to guide the regulation of the evaporation temperature. Occasional surveys of all thermoelements were made to indicate any irregularities in behavior. The current and potential drop in the calorimeter heater were observed on alternate minutes, starting one half minute after the power was switched on.

At the end of the chosen number of minutes, the current was switched back from the calorimeter heater to the substitute resistor, making the time 
factor of the energy an integral number of minutes as determined by the standard clock. The throttle valve was kept open long enough after the power was switched off to bring the calorimeter and contents to final equilibrium temperature near the initial temperature, usually within $0.01^{\circ} \mathrm{C}$. After a pause of 10 minutes for attaining equilibrium, the final temperature was observed. Following that observation, and while changing container and weighing a previous sample, a blank experiment was conducted to obtain the residual heat-leak factor, previously described.

On most of the samples, experiments were made at several rates of evaporation, usually between $1 / 4$ and $1 \mathrm{~g}$ per minute. Smaller rates than $1 / 4 \mathrm{~g}$ a minute were also used when necessary either because of limitations on account of the fluid characteristics, or else because of the limited amount of sample. The practice of using different rates of evaporation was a precaution to test for some conceivable source of error.

This practice has been followed for the past 30 years as a check on the various preventive measures for avoiding liquid mixed with the vapor in evaporation experiments. During the experiments on water, these measures had been so effective that no case was ever found where this change of rate gave a positive test for wet steam, even over the range from the ice point to within 1 degree of the critical temperature. In spite of this experience, the test has been continued as a routine safeguard against erroneous evaluation of the state of the vapor.

In the present case, if spray projected upward from the evaporating surface had escaped capture by the baffles and had been withdrawn with the vapor, the measured energy per unit mass would have been too small. Furthermore, if the temperature of the vapor indicated by the observation of $J_{5}$ thermoelement had been in error, the effect of the error might depend on the rate of flow. Absence of any evidence of the rate effect on the resulting value of the heat of vaporization, may be taken as contributing to the reliability of the results as far as the state of the fluid is concerned. Here again, it must be confessed the test showed no evidence of liquid mixed with the vapor. The baffles evidently have done their bit. Further evidence of reliability, as distinguished from consistency, was furnished by the experiments on water with this calorimeter.

\section{Results of Vaporization Experiments}

The results of the vaporization experiments are given in chronological order in table 1 . The values of net energy, given in column 6 , include not only the electrical energy input, but also the energies due to the various heat leaks (envelope, tube, and residual), the correction for the change in temperature of the calorimeter between the beginning and the end of the experiment, and the correction for any deviation of the evaporation temperature from the desired even temperature (usually $25^{\circ} \mathrm{C}$ ). These components of the net energy are not listed separately, because the corrections are so small. In an average experiment, the arithmetical sum of all the heat leak corrections amounts only to about 1 joule, whereas the other corrections are even less. This is the result of careful control of the temperature of the calorimeter and its surroundings at all times during an experiment.

TABLE 1. Results of vaporization experiments

WATER

\begin{tabular}{|c|c|c|c|c|c|c|c|c|}
\hline Date & $\begin{array}{l}\text { Tem- } \\
\text { pera- } \\
\text { ture }\end{array}$ & Mass & $\begin{array}{c}\text { Evap- } \\
\text { ora- } \\
\text { tion } \\
\text { rate }\end{array}$ & $\begin{array}{l}\text { Net } \\
\text { energy }\end{array}$ & $\gamma$ & Mean $\gamma_{25}$ & $\beta_{25}$ & $L_{25}$ \\
\hline & ${ }^{\circ} \mathrm{C}$ & $g$ & $\begin{array}{l}\text { g/min }- \\
\text { ute }\end{array}$ & int. $j$ & int. $j / g$ & int. $j / g$ & ${ }_{j / g}^{i n t .}$ & int. $j / g$ \\
\hline $11-8-41=$ & 25.0 & 9. 8792 & 0.49 & 24113.5 & 2440.83 & & & \\
\hline Do & 25.0 & 9.8929 & .49 & 24144.1 & 2440.55 & & & \\
\hline $11-10-41$. & 25.0 & 20. 2042 & .51 & 49326.3 & 2441. 39 & & & \\
\hline Do & 25.0 & 10.1150 & .51 & 24689.6 & 2440.89 & 2441.14 & 0.06 & 2441.08 \\
\hline Do_... & 25.0 & 10.1164 & .51 & 24694.0 & 2441.32 & & & \\
\hline Do & 25.0 & 10.1181 & 51 & 24699.3 & 2441.10 & & & \\
\hline $11-12-41$ & 25.0 & 9.8179 & .49 & 23974.6 & 2441. 93 & & & \\
\hline
\end{tabular}

$n$-HEPTANE

\begin{tabular}{|c|c|c|c|c|c|c|c|c|}
\hline $11-21-41$ & 25.0 & 9. 7943 & 0.49 & 3573.83 & 364.89 & \multirow{10}{*}{364.81} & \multirow{10}{*}{0.13} & \multirow{10}{*}{364.68} \\
\hline Do & 25.0 & 9.8035 & .49 & 3575.86 & 364.75 & & & \\
\hline Do & 25.0 & 9.8061 & .49 & 3577.23 & 364.80 & & & \\
\hline Do.... & 25.0 & 9.8114 & .49 & 3578.55 & 364.73 & & & \\
\hline Do_... & 25.0 & 14. 7147 & .49 & 5367.19 & 364.75 & & & \\
\hline $11-26-41$ & 25.0 & 9. 8281 & .49 & 3586.31 & 364.90 & & & \\
\hline Do & 25.0 & 4. 9249 & .25 & 1796.56 & 364. 79 & & & \\
\hline Do & 25.0 & 19.8554 & .99 & 7244.12 & 364.84 & & & \\
\hline Do & 15.0 & 9.6531 & .48 & 3580.46 & 370.91 & & & \\
\hline Do.... & 35.0 & 9.9843 & .50 & 3582.81 & 358.84 & & & \\
\hline
\end{tabular}

2,2,4-TRIMETHYLPENTANE

\begin{tabular}{|c|c|c|c|c|c|c|c|c|}
\hline $12-8-41 \ldots$ & 25.0 & 11.6222 & 0.58 & 3575.88 & 307.68 & & & \\
\hline Do & 25.0 & 11.4883 & .57 & 3534.26 & 307.64 & 30762 & 0.14 & 307.48 \\
\hline Do.... & 25.0 & 17.0507 & .57 & 5244. 24 & 307.57 & 301.02 & 0.14 & $30 \% .40$ \\
\hline Do & 25.0 & 13.5587 & .57 & 4170.72 & 307.60 & & & \\
\hline
\end{tabular}


TABLE 1. Results of vaporization experiments-Continued $n$-OCTANE

\begin{tabular}{|c|c|c|c|c|c|c|c|c|}
\hline Date & $\begin{array}{l}\text { Tem- } \\
\text { pera- } \\
\text { ture }\end{array}$ & Mass & $\begin{array}{c}\text { Evap- } \\
\text { ora- } \\
\text { tion } \\
\text { rate }\end{array}$ & $\begin{array}{l}\text { Net } \\
\text { energy }\end{array}$ & $\gamma$ & Mean $\gamma_{25}$ & $\beta_{25}$ & $L_{25}$ \\
\hline $12-16-41$ & $\begin{array}{c}{ }^{\circ} \mathrm{C} \\
25.0\end{array}$ & $\begin{array}{c}g \\
\text { 9. } \\
9070\end{array}$ & $\begin{array}{c}g / \text { min- } \\
\text { ute } \\
0.50\end{array}$ & $\begin{array}{c}\text { int. } j \\
3597.96\end{array}$ & $\begin{array}{r}\text { int. } j / g \\
363.17\end{array}$ & & $\begin{array}{l}\text { int. } \\
j^{\prime} / g\end{array}$ & int. $j / g$ \\
\hline Do & 25.0 & 9. 8989 & .50 & 3594.77 & 363.15 & 363.16 & 0.05 & 363.11 \\
\hline Do & 25.0 & 11.8834 & .50 & 4315.26 & 363. 13 & & & \\
\hline Do & 25.0 & 9. 9041 & .50 & 3596.89 & 363.17 & & & \\
\hline
\end{tabular}

2-METHYLHEPTANE

\begin{tabular}{|c|c|c|c|c|c|c|c|c|}
\hline $1-2-42 \ldots$ & 25.0 & 10. 4334 & 0.52 & 3624.17 & 347.36 & \multirow{4}{*}{347.37} & \multirow{4}{*}{0.07} & \multirow{4}{*}{347.30} \\
\hline Do & 25.0 & 10.0047 & .50 & 3474.39 & 347.28 & & & \\
\hline Do & 25.0 & 9. 9425 & .50 & 3454. 33 & 347.43 & & & \\
\hline Do.... & 25.0 & 15. 3498 & .50 & 5332.69 & 347.41 & & & \\
\hline
\end{tabular}

3-METHYLHEPTANE

\begin{tabular}{|c|c|c|c|c|c|c|c|c|}
\hline $1-8-42$ & 25.0 & 9. 9119 & 0.50 & 3455.64 & 348.64 & \multirow{4}{*}{ 348. 72} & \multirow{4}{*}{0.06} & \multirow{4}{*}{348.66} \\
\hline Do & 25.0 & 10.1243 & .51 & 3530.14 & 348.68 & & & \\
\hline Do & 25.0 & 10.5008 & .52 & 3662.60 & 348.79 & & & \\
\hline Do.... & 25.0 & 15.4967 & .50 & 5405.06 & 348.79 & & & \\
\hline
\end{tabular}

4-METHYLHEPTANE

\begin{tabular}{|c|c|c|c|c|c|c|c|c|}
\hline $1-14-42$ & 25.0 & 10.1086 & 0.50 & 3511,86 & 347.41 & \multirow{4}{*}{347.34} & \multirow{4}{*}{0.06} & \multirow{4}{*}{347.28} \\
\hline Do & 25.0 & 10.0087 & .50 & 3475.75 & 347.27 & & & \\
\hline Do.... & 25.0 & 10.0098 & .50 & 3476.55 & 347.31 & & & \\
\hline Do.... & 25.0 & 16.0145 & .50 & 5563.06 & 347.38 & & & \\
\hline
\end{tabular}

2,5-DIMEHTYLHEXANE

\begin{tabular}{|c|c|c|c|c|c|c|c|c|}
\hline $1-26-42$ & 25.0 & 20.9621 & 0.52 & 6948. 34 & 331.47 & & & \\
\hline Do.... & 25.0 & 22.1241 & .50 & 7333.70 & 331.48 & 331.48 & 0.09 & 331.39 \\
\hline
\end{tabular}

$n$-NONANE

\begin{tabular}{|c|c|c|c|c|c|c|c|c|}
\hline $2-4-42 \ldots$ & 25.0 & 19. 1859 & 0.48 & 6946. 08 & 362.04 & & & \\
\hline Do & 25.0 & 20.0269 & .50 & 7249.45 & 361.99 & 362.04 & 0.02 & 362.02 \\
\hline Do & 25.0 & 16.8176 & .47 & 6089. 36 & $36 \% .08$ & & & \\
\hline
\end{tabular}

$n$-DECANE

\begin{tabular}{|c|c|c|c|c|c|c|c|c|}
\hline $2-11-42$ & 25.0 & 4. 6160 & 0.15 & 1665. 79 & 360.87 & & & \\
\hline Do & 25.0 & 8. 3058 & .15 & 2999.02 & 361.08 & 360.97 & 0.01 & 360.96 \\
\hline Do.... & 25.0 & 7. 0784 & .15 & 2555.08 & 360.97 & & & \\
\hline
\end{tabular}

\section{2,3,4-TRIMETHYLPENTANE}

\begin{tabular}{r|r|r|r|r|r|r|r|r}
\hline 2-16-42_- & 25.0 & 9.7186 & 0.49 & 3208.08 & 330.10 & 330.14 & 0.08 & 330.06 \\
Do-_- & 25.0 & 19.9360 & .50 & 6582.39 & 330.18 & 330.14 & & \\
\hline
\end{tabular}

TABLE 1. Results of vaporization experiments-Continued 2,3,3-TRIMETHYLPENTANE

\begin{tabular}{|c|c|c|c|c|c|c|c|c|}
\hline Date & $\begin{array}{l}\text { Tem- } \\
\text { pera- } \\
\text { ture }\end{array}$ & Mass & $\begin{array}{c}\text { Evap- } \\
\text { ora- } \\
\text { tion } \\
\text { rate }\end{array}$ & $\begin{array}{c}\text { Net } \\
\text { energy }\end{array}$ & $\gamma$ & Mean $\gamma_{25}$ & $\beta_{25}$ & $L_{25}$ \\
\hline & ${ }^{\circ} \mathrm{C}$ & $g$ & $\begin{array}{c}g / \min \\
\text { ute }\end{array}$ & int. $j$ & $i n t . j / g$ & int.j/g & $\begin{array}{l}\text { int. } \\
\text { j/g }\end{array}$ & int. $j ! g$ \\
\hline $2-20-42--$ & 25.0 & 9. 8043 & 0.49 & 3192.19 & 325.59 & & & \\
\hline Do & 25.0 & 15.8101 & 1.58 & 5153.44 & 325.96 & & & \\
\hline Do.... & 25.0 & 10. 0081 & 0.50 & 3262.69 & 326.00 & 325,83 & 0.07 & 325.76 \\
\hline Do.... & 25.0 & 6. 9949 & .25 & 2278.50 & 325.74 & & & \\
\hline Do & 25.0 & 9. 7430 & .49 & 3174.88 & 325.86 & & & \\
\hline
\end{tabular}

WATER

\begin{tabular}{|c|c|c|c|c|c|c|c|c|}
\hline $2-25-42$ & 45.0 & 6. 3300 & 0.16 & 15156.6 & 2394.40 & \multirow{5}{*}{2441.47} & \multirow{5}{*}{0.06} & \multirow{5}{*}{2441.41} \\
\hline $2-26-42$ & 25.0 & 10. 2526 & .51 & 25031. 2 & 2441.45 & & & \\
\hline Do & 25.0 & 6. 2581 & .16 & 15278.6 & 2441.41 & & & \\
\hline Do & 25.0 & 7. 7441 & .29 & 18906.6 & 2441.42 & & & \\
\hline Do & 25.0 & 7. 9806 & .50 & 19485.4 & 2441.59 & & & \\
\hline
\end{tabular}

3,3-DIMETHYLHEXANE

\begin{tabular}{|c|c|c|c|c|c|c|c|c|}
\hline $3-13-42$ & 25.0 & 10. 2026 & 0.51 & 3352.59 & 328.60 & & & \\
\hline Do & 25.0 & 25.0234 & 1.00 & 8223.19 & 328.62 & 32863 & 08 & 398.55 \\
\hline Do.... & 25.0 & 8. 0078 & 0.56 & 2631.99 & 328.68 & 328.03 & 0.08 & 328.55 \\
\hline Do.... & 25.0 & 10.0140 & .50 & 3290.75 & 328.61 & & & \\
\hline
\end{tabular}

2,3-DIMETHYLHEXANE

\begin{tabular}{r|r|r|r|r|r|r|r|r}
\hline & & & & & & \\
$3-20-42 \ldots$ & 25.0 & 9.3631 & 0.47 & 3180.34 & 339.67 & & & \\
Do__-_ & 25.0 & 18.5009 & .97 & 6282.68 & 339.59 & & & \\
Do $\ldots \ldots$ & 25.0 & 7.8080 & .24 & 2650.99 & 339.52 & 339.61 & 0.07 & 339.54 \\
Do__- & 25.0 & 11.1902 & .49 & 3800.96 & 339.67 & & & \\
\hline
\end{tabular}

\section{2,2,3-TRIMETHYLPENTANE}

\begin{tabular}{|c|c|c|c|c|c|c|c|c|}
\hline $3-23-42$ & 25.0 & 8. 0612 & 0.50 & 2606.23 & 323.30 & & & \\
\hline Do & 25.0 & 8.1525 & 1.02 & 2635.12 & 323.23 & 32320 & 0,08 & 323 \\
\hline Do.... & 25.0 & 8. 1516 & 0.26 & 2633.63 & 323.08 & 523.20 & 0.08 & 525.12 \\
\hline Do.... & 25.0 & 7. 5364 & .05 & 2435. 74 & 323.20 & & & \\
\hline
\end{tabular}

\section{$n$-HEXANE}

\begin{tabular}{|c|c|c|c|c|c|c|c|c|}
\hline $3-24-42 \ldots$ & 25. 0 & 8. 9398 & 0.45 & 3276.73 & 366.53 & & & \\
\hline Do & 25.0 & 14. 5929 & .91 & 5347.23 & 366.43 & $366 \quad 44$ & 0.39 & 36605 \\
\hline Do.... & 25. 0 & 7. 9004 & .25 & 2894.89 & 366.42 & 300.44 & 0.39 & 306.05 \\
\hline Do.... & 25.0 & 10.8156 & .49 & 3962.52 & 366.37 & & & \\
\hline
\end{tabular}

\section{2-METHYL-3-ETHYLPENTANE}

\begin{tabular}{|c|c|c|c|c|c|c|c|c|}
\hline $3-26-42$ & 25.0 & 9.7119 & 0.49 & 3275.51 & 337.27 & & & \\
\hline Do & 25.0 & 15. 5975 & .98 & 5259. 28 & 337. 19 & 33725 & 007 & 337.18 \\
\hline Do.... & 25.0 & 7. 6845 & .24 & 2591. 52 & 337.24 & 503.20 & 0.07 & 501.10 \\
\hline Do & 25.0 & 11. 6749 & .48 & 3938.02 & 337.31 & & & \\
\hline
\end{tabular}


TABle 1. Results of vaporization experiments-Continued 3-METHYL-3-ETHLYPENTANE

\begin{tabular}{|c|c|c|c|c|c|c|c|c|}
\hline Date & $\begin{array}{l}\text { Tem- } \\
\text { pera- } \\
\text { ture }\end{array}$ & Mass & $\begin{array}{c}\text { Evap- } \\
\text { ora- } \\
\text { tion } \\
\text { rate }\end{array}$ & $\begin{array}{c}\text { Net } \\
\text { energy }\end{array}$ & $\gamma$ & Mean $\gamma_{25}$ & $\boldsymbol{\beta}_{25}$ & $L_{25}$ \\
\hline $\begin{array}{r}3-27-42 \ldots \\
\text { Do } \\
\text { Do } \\
\text { Do } \ldots\end{array}$ & $\begin{array}{l}{ }^{\circ} \mathrm{C} \\
25.0 \\
25.0 \\
25.0 \\
25.0\end{array}$ & $\begin{array}{r}g \\
9.9786 \\
15.9652 \\
7.9748 \\
11.9768\end{array}$ & $\begin{array}{c}g / \min - \\
\text { ute } \\
0.50 \\
1.00 \\
0.25 \\
.50\end{array}$ & $\begin{array}{c}\text { int. } j \\
3319.54 \\
5309.69 \\
2652.30 \\
3982.73\end{array}$ & $\begin{array}{c}\text { int. } j / g \\
332.67 \\
332.58 \\
332.58 \\
332.54\end{array}$ & int. $j / g$ & $\begin{array}{l}\text { int. } \\
\text { j/g }\end{array}$ & int. $j / g$ \\
\hline
\end{tabular}

2,2-DIMETHYLHEXANE

\begin{tabular}{|c|c|c|c|c|c|c|c|c|}
\hline $3-30-42-$ & 25. 0 & 9.0189 & 0.50 & 2945.01 & 326.54 & & & \\
\hline Do & 25.0 & 9. 9168 & .99 & 3237.56 & 326.48 & 326.40 & $0-00$ & 206,4 \\
\hline Do $\ldots$ & 25.0 & 7. 9673 & .25 & 2601.09 & 326.47 & 326.49 & 0.09 & 326.40 \\
\hline Do_... & 25.0 & 9. 0576 & .50 & 2957.02 & 326.47 & & & \\
\hline
\end{tabular}

\section{3-ETHYLHEXANE}

\begin{tabular}{|c|c|c|c|c|c|c|c|}
\hline $3-31-42-25.0$ & 9. 4628 & 0.47 & 3284.57 & 347.11 & & & \\
\hline Do_._. 25.0 & 19.9138 & .95 & 6911.25 & 347.06 & 347.07 & 0.06 & 347.01 \\
\hline Do_... 25.0 & 7. 5362 & .24 & 2615.46 & 347.05 & & & \\
\hline
\end{tabular}

\section{METHYLCYCLOHEXANE}

\begin{tabular}{|c|c|c|c|c|c|c|c|c|}
\hline $4-7-42 \ldots$ & 25.0 & 9.1250 & 0.46 & 3287.94 & 360.32 & & & \\
\hline Do & 25.0 & 11.9260 & 1.00 & 4295.67 & 360.19 & 360.19 & 0,13 & 360.06 \\
\hline Do_... & 25.0 & 19. 9239 & 1.00 & 7175.15 & 360.13 & 500.19 & 0.15 & 300.00 \\
\hline Do_... & 25.0 & 9. 9962 & .50 & 3599.86 & 360.12 & - & & \\
\hline
\end{tabular}

\section{CYCLOHEXANE}

\begin{tabular}{r|r|r|r|r|r|r|r|r}
\hline 4-9-42_.. & 25.0 & 9.2557 & 0.46 & 3634.88 & 392.72 \\
Do_..- & 25.0 & 29.6289 & .99 & 11634.91 & 392.69 \\
Do_..- & 25.0 & 11.9967 & .50 & 4711.61 & 392.74 & 392.72 & 0.24 & 392.48 \\
\hline
\end{tabular}

\section{ETHYLCYCLOHEXANE}

\begin{tabular}{|c|c|c|c|c|c|c|c|c|}
\hline $4-10-42$ & 25.0 & 10. 1008 & 0.50 & 3643.67 & 360.73 & & & \\
\hline Do & 25.0 & 27. 5431 & .93 & 9933.49 & 360.65 & 360.68 & 0.05 & 360.63 \\
\hline Do_... & 25.0 & 13. 0929 & .50 & 4722.00 & 360.65 & & & \\
\hline
\end{tabular}

n-PROPYLCYCLOHEXANE

\begin{tabular}{l|l|l|l|l|l|l|l|l}
\hline $\mathbf{4 - 1 7 - 4 2 - -}$ & 25.0 & 37.8146 & 0.51 & 13504.76 & 357.13 & 357.13 & 0.02 & 357.11 \\
\hline
\end{tabular}

cis-1,2-DIMETHYLCYCLOHEXANE

\begin{tabular}{|c|c|c|c|c|c|c|c|c|}
\hline & 250 & 14. 4052 & 0.51 & 5098.87 & 353.96 & & & \\
\hline Do & 25.0 & 18. 2952 & .91 & 6475.32 & 353.94 & 353.92 & 0.06 & 353.86 \\
\hline Do & 25.0 & 15.5325 & .51 & 5496.40 & 353.86 & & & \\
\hline
\end{tabular}

TABLE 1. Results of vaporization experiments-Continued trans-1,2-DIMETHYLCYCLOHEXANE

\begin{tabular}{|c|c|c|c|c|c|c|c|c|}
\hline Date & $\begin{array}{l}\text { Tem- } \\
\text { pera- } \\
\text { ture }\end{array}$ & Mass & $\begin{array}{c}\text { Evap- } \\
\text { ora- } \\
\text { tion } \\
\text { rate }\end{array}$ & $\begin{array}{c}\text { Net } \\
\text { energy }\end{array}$ & $\gamma$ & Mean $\gamma_{25}$ & $\beta_{25}$ & $L_{25}$ \\
\hline $4-21-42=-$ & $\begin{array}{c}{ }^{\circ} \mathrm{C} \\
25.0\end{array}$ & $\begin{array}{c}g \\
\text { 10. } 3778\end{array}$ & $\begin{array}{c}\text { g/min }- \\
\text { ute } \\
0.52\end{array}$ & $\begin{array}{c}\text { int. } j \\
3547.68\end{array}$ & $\begin{array}{r}\text { int. } j / g \\
341.85\end{array}$ & int. $j / g$ & $\begin{array}{l}\text { int. } \\
j / g\end{array}$ & int. $j / g$ \\
\hline Do & 25.0 & 30.0590 & 1.00 & 10274.63 & 341.82 & 341.84 & 0.07 & 341.77 \\
\hline Do_... & 25.0 & 10. 0039 & .50 & 3419.85 & 341.85 & & & \\
\hline
\end{tabular}

trans-1,3-DIMETHYLCYCLOHEXANE \&

\begin{tabular}{r|r|r|r|r|r|r|r|r}
\hline $1-22-42 \ldots$ & 25.0 & 9.7593 & 0.49 & 3409.64 & 349.37 \\
Do _._ & 25.0 & 10.0295 & 1.00 & 3503.73 & 349.34 & 349.34 & 0.07 & 349.27 \\
Do_... & 25.0 & 30.0002 & 1.00 & 10479.26 & 349.31 & & & \\
& & & & & &
\end{tabular}

cis-1,3-DIMETHYLCYCLOHEXANE b

\begin{tabular}{|c|c|c|c|c|c|c|c|c|}
\hline $4-24-42$ & 25.0 & 10.0416 & 0.50 & 3421.84 & 340.77 & & & \\
\hline Do & 25.0 & 30.9169 & 1. 03 & 10531.87 & 340.65 & 340.70 & 0.08 & 340.62 \\
\hline Do.... & 25.0 & 10.0596 & .50 & 3427.22 & 340.69 & & & \\
\hline
\end{tabular}

cis-1,4-DIMETHYLCYCLOHEXANE

\begin{tabular}{|c|c|c|c|c|c|c|c|c|}
\hline $4-27-42$ & 25.0 & 9. 8297 & 0.49 & 3419.41 & 347.86 & & & \\
\hline Do & 25. 0 & 29.4440 & .98 & 10241. to & 31782 & 347.84 & 0.07 & 347.77 \\
\hline Do_... & 25.0 & 9.8533 & .49 & 3427.38 & 347.84 & & & \\
\hline
\end{tabular}

\section{2,3-DIMETHYLPENTANE (IMPURE)}

\begin{tabular}{|c|c|c|c|c|c|c|c|c|}
\hline $4-28-42$ & 25.0 & 11. 7759 & 0.56 & 4027.50 & 342.01 & & & \\
\hline Do & 25.0 & 10.0438 & 1.00 & 3436.17 & 342.12 & 342.10 & 0.13 & $(341.97)^{\circ}$ \\
\hline Do .... & 25.0 & 9. 9292 & .50 & 3397.54 & 342.18 & & & \\
\hline
\end{tabular}

2,3-DIMETHYLPENTANE (PURE)

\begin{tabular}{|c|c|c|c|c|c|c|c|c|}
\hline $4-29-42$ & 25.0 & 10. 1601 & 0.51 & 3472.74 & 341.80 & & & \\
\hline Do & 25.0 & 10.1885 & 1. 02 & 3482.06 & 341.76 & 341.77 & 0.13 & 341.64 \\
\hline Do .... & 25. 0 & 10.0369 & 0.50 & 3430.10 & 341.75 & & & \\
\hline
\end{tabular}

3,3-DIMETHYLPENTANE

\begin{tabular}{|c|c|c|c|c|c|c|c|c|}
\hline $4-29-42 \ldots$ & 25.0 & 7. 7358 & 0.52 & 2550.61 & 329. 72 & 329.70 & & \\
\hline Do & 25.0 & 6. 1893 & .52 & 2040.40 & 329.67 & 329.70 & 0.20 & 329.50 \\
\hline
\end{tabular}

2,2-DIMETHYLPENTANE

\begin{tabular}{r|r|r|r|r|r|r|r|r}
\hline & & & & & \\
\hline Do $30-42 \ldots$ & 25.0 & 10.5002 & 0.52 & 3400.38 & 323.84 & 323.82 & 0.27 & 323.55 \\
\hline
\end{tabular}

a This isomer, formerly labeled "cis", has the following properties: boiling point at $1 \mathrm{~atm} ., 124.45^{\circ} \mathrm{C}$; refractive index, $r_{D} \mathrm{~S}$ at $25^{\circ} \mathrm{C}, 1.4284$; density, at $25^{\circ} \mathrm{C}, 0.7806 \mathrm{~g} / \mathrm{ml}$.

b This isomer, formerly labeled "trans", has the following properties: boiling point at $1 \mathrm{~atm} ., 120.09^{\circ} \mathrm{C}$; refractive index, $n_{D} \mathrm{~S}$ at $25^{\circ} \mathrm{C}, 1.4206$; density at $25^{\circ} \mathrm{C}, 0.7620 \mathrm{~g} / \mathrm{ml}$.

c Sample of lower purity. 
TABLE 1. Results of vaporization experiments-Continued 2,2-DIMETHYLBUTANE (SILICA GEL DRYING)

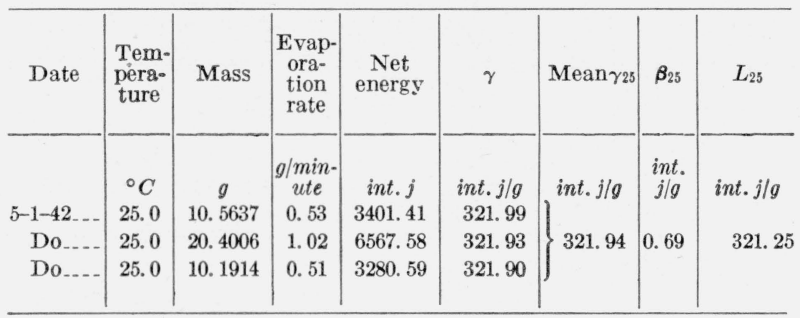

2,2-DIMETHYLBUTANE (FREEZE OUT WATER)

\begin{tabular}{|c|c|c|c|c|c|c|c|c|}
\hline $5-8-42 \ldots$ & 25.0 & 10.5422 & 0.53 & 3391.52 & 321.71 & & & \\
\hline Do & 25.0 & 15. 3726 & 1.02 & 4949. 10 & 321.94 & 321.93 & 0.69 & 321.24 \\
\hline Do_... & 25.0 & 10.2099 & 0.51 & 3288.96 & 322.14 & & & \\
\hline
\end{tabular}

$\mathrm{P}_{2} \mathrm{O}_{3}$ DRYING

\begin{tabular}{|c|c|c|c|c|c|c|c|c|}
\hline $5-20-42$ & 25.0 & 10.0734 & 0.50 & 3243.28 & 321.96 & & & \\
\hline Do & 25.0 & 20.4435 & 1.02 & 6580.97 & 321.91 & 321.96 & 0.69 & 321.27 \\
\hline Do.... & 25.0 & 10.0818 & 0.50 & 3246.24 & 321.99 & & & \\
\hline
\end{tabular}

\section{$N$-PENTANE}

\begin{tabular}{|c|c|c|c|c|c|c|c|c|}
\hline $5-14-42$ & 25.0 & 9.8235 & 0.45 & 3610.02 & 367.49 & & & \\
\hline Do & 25.0 & 14. 3765 & .90 & 5282.25 & 367.42 & 367.44 & 1. 22 & 366. 22 \\
\hline Do & 25.0 & 9. 8489 & .45 & 3618.69 & 367.42 & & & \\
\hline
\end{tabular}

2,2,3-TRIMETHYLBUTANE

\begin{tabular}{r|r|l|l|l|l|l|l|l}
\hline 5-15-42_- & 25.0 & 10.1184 & 0.50 & 3236.38 & 319.85 & & & \\
Do_.-. & 25.0 & 14.3947 & 1.03 & 4606.24 & 320.00 \\
Do_-- & 25.0 & 10.1393 & 0.51 & 3244.22 & 319.96 & 319.94 & 0.24 & 319.70 \\
\hline
\end{tabular}

\section{trans-1,4-DIMETHYLCYCLOHEXANE (SILICA GEL DRYING)}

\begin{tabular}{r|r|r|r|r|r|r|r|r}
\hline 5-18-42_- & 25.0 & 9.6050 & 0.48 & 3242.61 & 337.60 & \} & & \\
Do--.- & 25.0 & 23.5953 & .48 & 7963.61 & 337.51 & 337.56 & 0.08 & 337.48 \\
\hline
\end{tabular}

\section{$\mathrm{P}_{2} \mathrm{O}_{3}$ DRYING}

\begin{tabular}{r|r|r|r|r|r|r|r|r}
\hline 5-21-42_- & 25.0 & 9.6064 & 0.48 & 3244.39 & 337.73 & & & \\
D0_-_- & 25.0 & 19.4755 & .97 & 6573.17 & 337.51 \\
Do.--- & 25.0 & 9.6463 & .48 & 3256.04 & 337.54 & 337.58 & 0.08 & 337.50 \\
\hline
\end{tabular}

\section{2-METHYLPENTANE}

\begin{tabular}{|c|c|c|c|c|c|c|c|c|}
\hline $5-26-42$ & 25.0 & 9.3458 & 0.47 & 3243.65 & 347.07 & & & \\
\hline Do & 25.0 & 18. 9891 & .95 & 6589.01 & 346. 99 & 347.10 & 0.57 & 346.53 \\
\hline Do & 25.0 & 9. 3494 & .47 & 3246.47 & 347.24 & & & \\
\hline
\end{tabular}

\section{3-METHYLPENTANE}

\begin{tabular}{r|r|r|r|r|r|r|r|r}
\hline $5-27-42 \ldots$ & 25.0 & 9.6878 & 0.48 & 3406.42 & 351.62 \\
Do_-. & 25.0 & 19.2642 & .96 & 6775.16 & 351.70 \\
Do_.-. & 25.0 & 10.0978 & .50 & 3551.57 & 381.72 & 351.68 & 0.45 & 351.23 \\
\hline
\end{tabular}

TABLE 1. Results of vaporization experiments-Continued METHYLCYCLOPENTANE

\begin{tabular}{|c|c|c|c|c|c|c|c|c|}
\hline Date & $\begin{array}{l}\text { Tem- } \\
\text { pera- } \\
\text { ture }\end{array}$ & Mass & $\begin{array}{c}\text { Evap- } \\
\text { ora- } \\
\text { tion } \\
\text { rate }\end{array}$ & $\begin{array}{c}\text { Net } \\
\text { energy }\end{array}$ & $\gamma$ & Mean $\gamma_{25}$ & $\beta_{25}$ & $L_{2 s}$ \\
\hline $5-28-42$ & $\begin{array}{c}{ }^{\circ} \mathrm{C} \\
25.0\end{array}$ & $\begin{array}{c}g \\
9.4348\end{array}$ & $\begin{array}{c}g / \text { min }- \\
\text { ute } \\
0.47\end{array}$ & $\begin{array}{c}\text { int. } j \\
3549.01\end{array}$ & $\begin{array}{l}\text { int } j / g \\
376.16\end{array}$ & int.j/g & $\underset{j / g}{i n t .}$ & int. $j / g$ \\
\hline Do & 25.0 & 18. 9391 & .95 & 7123.43 & 376.12 & 376.12 & 0.34 & 375.78 \\
\hline Do .... & 25.0 & 9.4495 & .47 & 3553.84 & 376.09 & & & \\
\hline
\end{tabular}

\section{n-PROPYLCYCLOPENTANE}

\begin{tabular}{r|r|r|r|r|r|r|r|r}
\hline $5-29-42 \ldots$ & 25.0 & 9.9500 & 0.50 & 3643.93 & 366.22 & & & \\
Do_.-- & 25.0 & 13.7873 & 1.00 & 5047.64 & 366.11 & 366.17 & 0.05 & 366.12 \\
\hline
\end{tabular}

\section{ISOPROPYLCYCLOPENTANE}

\begin{tabular}{|c|c|c|c|c|c|c|c|c|}
\hline $6-1-42$. & 25.0 & 8. 3058 & 0.52 & 2920.95 & 351.68 & & & \\
\hline Do & 25.0 & 8. 2092 & 1.02 & 2886.39 & 351.60 & 351.61 & 0.06 & 351.55 \\
\hline Do_.. & 25.0 & 8. 3280 & 0.52 & 2927.75 & 351.56 & & & \\
\hline
\end{tabular}

\section{2, 4-DIMETHYLHEXANE}

\begin{tabular}{r|r|r|r|r|r|r|r|r}
\hline & & & & & \\
6-2-42-- & 25.0 & 11.0514 & 0.55 & 3654.85 & 330.71 \\
Do-_-- & 25.0 & 21.7718 & 1.09 & 7198.65 & 330.64 \\
Do $25 .-$ & 25.0 & 11.0743 & 0.55 & 3661.46 & 330.63 & 330.66 & 0.09 & 330.57 \\
\hline
\end{tabular}

\section{3, 4-DIMETHYLHEXANE}

\begin{tabular}{|c|c|c|c|c|c|c|c|c|}
\hline $6-3-42$ & 25.0 & 10. 6941 & 0.54 & 3649. 51 & 341.26 & \multirow{3}{*}{341.23} & \multirow{3}{*}{0.07} & \multirow{3}{*}{341.16} \\
\hline Do & 25.0 & 23. 0734 & 1.05 & 7873.32 & 341.23 & & & \\
\hline Do & 25.0 & 10. 7099 & 0.54 & 3654.29 & 341.21 & & & \\
\hline \multicolumn{9}{|c|}{ BENZENE } \\
\hline $6-4-42$ & 25.0 & 10.4328 & 0.52 & 4522.37 & 433.48 & \multirow{3}{*}{433.47} & \multirow{3}{*}{0.20} & \multirow{3}{*}{433.27} \\
\hline Do & 25.0 & 29.7534 & .90 & 12897.76 & 433.49 & & & \\
\hline Do.... & 25.0 & 10.4071 & .52 & 4510.91 & 433.45 & & & \\
\hline
\end{tabular}

\section{TOLUENE}

\begin{tabular}{|c|c|c|c|c|c|c|c|c|}
\hline - & 25.0 & 10.9906 & 0.55 & 4532.32 & 412.38 & & & \\
\hline Do & 25.0 & 39. 9437 & 1.00 & 16473. 38 & 412.42 & 412.41 & 0.15 & 412. 26 \\
\hline Do_.. & 25.0 & 9.9466 & 0.50 & 4102,42 & 412.44 & & & \\
\hline
\end{tabular}

\section{m-XYLENE}

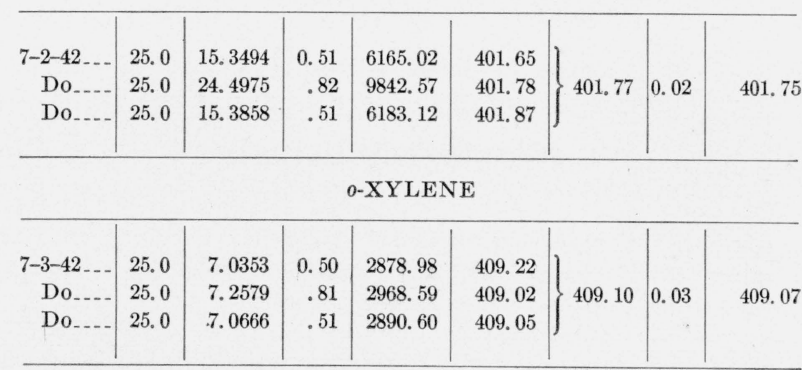


TABLE 1. Results of vaporization experiments-Continued $p$-XYLENE

\begin{tabular}{|c|c|c|c|c|c|c|c|c|}
\hline Date & $\begin{array}{l}\text { Tem- } \\
\text { pera- } \\
\text { ture }\end{array}$ & Mass & $\begin{array}{l}\text { Evap- } \\
\text { ora- } \\
\text { tion } \\
\text { rate }\end{array}$ & $\begin{array}{c}\text { Net } \\
\text { energy }\end{array}$ & $\gamma$ & Mean $_{\gamma_{25}}$ & $\boldsymbol{\beta}_{25}$ & $L_{25}$ \\
\hline $7-6-42 \ldots$ & $\begin{array}{c}{ }^{\circ} \mathrm{C} \\
25.0\end{array}$ & $\begin{array}{l}g \\
\text { 7. } 0780\end{array}$ & $\begin{array}{c}g / \min - \\
\text { ute } \\
0.51\end{array}$ & $\begin{array}{c}\text { int. } j \\
2825.44\end{array}$ & $\begin{array}{r}\text { int. } j / g \\
399.19\end{array}$ & int. $j / g$ & $\underset{j / g}{i n t .}$ & int. $j / g$ \\
\hline Do_..- & 25.0 & 7.1573 & .80 & 2856.82 & 399.15 & 399.14 & 0.03 & 399.1 \\
\hline Do & 25.0 & 6. 9596 & .50 & 2777.38 & 399.07 & & & \\
\hline
\end{tabular}

ETHYLBENZENE (IMPURE)

\begin{tabular}{|c|c|c|c|c|c|c|c|c|}
\hline $7-7-42 \ldots$ & 25.0 & 14. 8916 & 1.00 & 5922.79 & 397.73 & 397.72 & 0.05 & $(039767)$ \\
\hline Do_..- & 25.0 & 10.0133 & 0.50 & 3982.32 & 397. 70 & 580.12 & 0.00 & (203) \\
\hline
\end{tabular}

ETHYLBENZENE (PURE)

\begin{tabular}{c|r|r|r|r|r|r|r|r}
\hline $7-15-42--$ & 25.0 & 9.9914 & 0.50 & 3976.36 & 397.98 & & & \\
Do $-\ldots$ & 25.0 & 9.9927 & .50 & 3976.08 & 397.90 & 397.94 & 0.05 & 397.89 \\
\hline
\end{tabular}

$n$-PROPYLBENZENE

\begin{tabular}{r|r|r|r|r|r|r|r|r}
\hline 7-8-42_-- & 25.0 & 9.2470 & 0.46 & 3556.71 & 384.63 \\
Do---- & 25.0 & 9.2387 & .46 & 3552.74 & 384.55 & 384.59 & 0.01 & 384.58 \\
\hline
\end{tabular}

ISOPROPYLBENZENE

\begin{tabular}{|c|c|c|c|c|c|c|c|c|}
\hline - & & & & & & & & \\
\hline $7-14-42 \ldots$ & 25.0 & 11. 1185 & 0.46 & 4175.61 & 375.56 & & & \\
\hline Do & 25.0 & 13.5376 & .68 & 5083.95 & 375.54 & 375.55 & 0.02 & 375.53 \\
\hline Do_... & 25.0 & 9.4714 & .95 & 3557.09 & 375.56 & & & \\
\hline
\end{tabular}

\section{1,3,5-TRIMETHYLBENZENE}

\begin{tabular}{|c|c|c|c|c|c|c|c|c|}
\hline $7-17-42$ & 25.0 & 12.5212 & 0.25 & 4942.98 & 394.77 & 394.92 & 0.01 & 394.91 \\
\hline Do_... & 25.0 & 12.5059 & .25 & 4940.82 & 395.08 & $20 x \cdot 02$ & 0.01 & $80 x+01$ \\
\hline
\end{tabular}

\section{1,2,4-TRIMETHYLBENZENE}

\begin{tabular}{|c|c|c|c|c|c|c|c|c|}
\hline $7-20-42 \ldots$ & 25.0 & 9.9248 & 0.50 & 3958.02 & 398.80 & $200-70$ & 0 & \\
\hline Do & 25.0 & 9.9241 & .50 & 3957.40 & 398.77 & 398.78 & 0.01 & 398.77 \\
\hline
\end{tabular}

\section{1,2,3. TRIMETHYLBENZENE}

\begin{tabular}{r|r|r|r|r|r|r|r|r}
\hline $7-23-42 \ldots$ & 25.0 & 5.6214 & 0.11 & 2294.45 & 408.16 & & & \\
Do $\ldots--$ & 25.0 & 6.0106 & .12 & 2452.78 & 408.08 & 408.12 & 0.01 & 408.11 \\
\hline
\end{tabular}

\section{2,3,5-TRIMETHYLHEXANE}

\begin{tabular}{r|r|r|r|r|r|r|r|r}
\hline $7-24-42 \ldots-$ & 25.0 & 10.1306 & 0.51 & 3271.76 & 322.96 \\
Do_-_- & 25.0 & 10.1552 & 1.02 & 3279.28 & 322.92 & 322.95 & 0.04 & 322.91 \\
Do_--- & 25.0 & 10.0867 & 0.51 & 3257.71 & 322.97 & & & \\
\hline
\end{tabular}

- Sample of lower purity.
TABLE 1. Results of vaporization experiments-Continued 2,2,5-TRIMETHYLHEXANE

\begin{tabular}{|c|c|c|c|c|c|c|c|c|}
\hline Date & $\begin{array}{l}\text { Tem- } \\
\text { pera- } \\
\text { ture }\end{array}$ & Mass & $\begin{array}{c}\text { Evap- } \\
\text { ora- } \\
\text { tion } \\
\text { rate }\end{array}$ & $\begin{array}{c}\text { Net } \\
\text { energy }\end{array}$ & $\gamma$ & Mean $\gamma_{25}$ & $\boldsymbol{\beta}_{25}$ & $L_{25}$ \\
\hline $7-27-42$ & $\begin{array}{c}{ }^{\circ} \mathrm{C} \\
25.0\end{array}$ & $\begin{array}{c}g \\
\text { 10. } 4036\end{array}$ & $\begin{array}{c}\text { g/min }- \\
\text { ute } \\
0.52\end{array}$ & $\begin{array}{c}\text { int. } j \\
3259.14\end{array}$ & $\begin{array}{c}\text { int. } j / g \\
313.27\end{array}$ & & int. & int. $j / g$ \\
\hline Do & 25.0 & 10. 0603 & 1. 01 & 3150.79 & 313.19 & 313.22 & 0.04 & 313.18 \\
\hline Do... & 25.0 & 10.0192 & 0.52 & 3137.91 & 313.19 & & & \\
\hline
\end{tabular}

3-ETHYLPENTANE

\begin{tabular}{r|r|r|r|r|r|r|r|r}
\hline $7-28-42 \ldots$ & 25.0 & 8.9272 & 0.45 & 3139.44 & 351.67 \\
Do._- & 25.0 & 9.8968 & .99 & 3480.02 & 351.63 & 351.65 & 0.16 & 351.49 \\
\hline
\end{tabular}

2,4-DIMETHYLPENTANE

\begin{tabular}{r|r|r|r|r|r|r|r|r}
\hline $7-30-42 \ldots-$ & 25.0 & 10.3614 & 0.50 & 3403.05 & 328.44 \\
Do_-- & 25.0 & 9.9658 & 1.00 & 3273.15 & 328.44 \\
Do_--- & 25.0 & 9.0134 & 0.50 & 2960.38 & 328.44 & 328.44 & 0.25 & 328.17 \\
\hline
\end{tabular}

2,3-DIMETHYLBUTANE

\begin{tabular}{c|r|r|r|r|r|r|r|r}
\hline $7-31-42 \ldots$ & 25.0 & 3.8323 & 0.48 & 1297.46 & 338.56 & 338.50 & 0.61 & 337.89 \\
Do_-_- & 25.0 & 4.3122 & .48 & 1459.45 & 338.45 & \} 33.6 & & \\
\hline
\end{tabular}

HEXAMETHYLETHANE (SOLID)

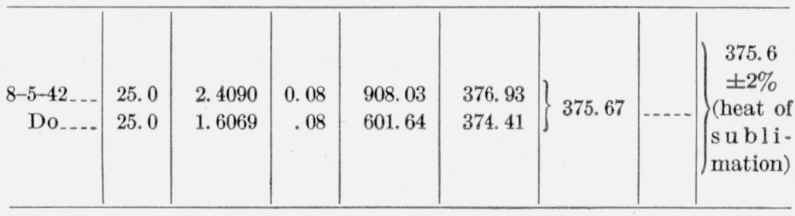

WATER

\begin{tabular}{|c|c|c|c|c|c|c|c|c|}
\hline $8-11-42$ & 25.0 & 6.3607 & 0.21 & 15536.4 & 2442.56 & & & \\
\hline Do & 25.0 & 6. 3691 & .21 & 15550.6 & 2441.57 & 2442.05 & 0.06 & 2441.99 \\
\hline Do.... & $\ldots \ldots$ & 6. 3694 & .21 & 15554. 2 & 2442. 02 & & & \\
\hline
\end{tabular}

The value of gamma, $\gamma$, given in column 6 , is obtained by division of the value of net energy (col. 5) by the mass (col. 3). This quantity, gamma, $\gamma$, is greater than the latent heat of vaporization by the quantity beta, $\beta$, as described previously [1] in the method. In algebraic form,

$$
L=\gamma-\beta \text {. }
$$

The quantity $\beta$, which is very small in most of the experiments, is calculated from the relation

$$
\beta=T v d p / d T
$$

where $T$ is absolute temperature, $v$ is specific volume of the liquid, and $d p / d T$ is the vapor pressure slope. Values of vapor pressure slope and 
liquid specific volume were calculated from data given in various sources $[14,15]$. As the quantity $\beta$ is small, high accuracy was not required in the source data. Calculated values of $\beta$ are listed in column 8 , and the derived values of heat of vaporization are listed in column 9.

Inspection of table 1 shows some duplication of experiments with a few materials. This was due either to an investigation of the effect of various drying methods, or to the availability of a purer sample at a later date. Ethylbenzene and 2,3dimethylpentane are examples of the latter, and values of heats of vaporization on both samples of different purity are given to show the small effect on the result. The differences are less than 0.1 percent. The hydrocarbons 2,2-dimethylbutane and trans-1,4-dimethylcyclohexane were chosen to investigate the different drying methods. The results using different drying methods agreed to better than 0.01 percent.

Measurements on the heat of vaporization of water were made before, during, and after the series of hydrocarbon experiments. This procedure served as an additional check on the accuracy of the results. The average of the 15 water experiments gave a value of heat of vaporization at $25^{\circ}$ $\mathrm{C}$ of 2441.37 int. $\mathrm{j} / \mathrm{g}$ as compared to 2441.40 obtained with an earlier calorimeter [4]. The average deviation from this earlier value was 0.015 percent.

\section{Accuracy of Results on Heat of Vaporization}

In view of the purity of the hydrocarbons, smallness of heat leaks, and the excellent agreement of the resulting heats of vaporization of water with those with a different calorimeter, it is believed unlikely that the error in the heats of vaporization of the hydrocarbons listed in table 1 is more than 0.1 percent. In the case of hexamethylethane, experimental difficulties due to the fact that the material was a solid at $25^{\circ} \mathrm{C}$ lead to an estimated probable error of about 2 percent in the observed heat of sublimation.

\section{Heat Capacity of Twelve Hydrocarbons}

\section{Introduction}

In addition to the measurements of heat of vaporization, measurements of liquid heat ca- pacity were undertaken, first in the temperature range $10^{\circ}$ to $35^{\circ} \mathrm{C}$, and later $5^{\circ}$ to $45^{\circ} \mathrm{C}$. After the first 12 hydrocarbons, however, the heat capacity measurements were discontinued to expedite the measurements on heat of vaporization.

The samples of hydrocarbons used in these measurements were the same as those used in the measurements of heat of vaporization. The apparatus was also the same, although the experimental procedure was quite different.

\section{Method}

As described in previous publications $[2,3,4]$ the method consists of heating the calorimeter with a sample of saturated fluid over a measured temperature range. By making two types of experiments, one with a small amount of liquid in the calorimeter (low filling) and the other with a large amount of liquid in the calorimeter (high filling), it is possible to account for the tare heat capacity of the calorimeter and to obtain the change of a quantity denoted by alpha, $\alpha$, which is a characteristic property of the fluid.

If $Q_{H}$ and $Q_{L}$ denote the measured quantities of heat added in the high and low filling experiments having masses of fluid $M_{H}$ and $M_{L}$ respectively, to heat the calorimeter from temperature $T_{1}$ to $T_{2}$, then it has been shown [1] that

$$
\begin{gathered}
Q_{H}=[Z]_{1}^{2}+M_{H}[\alpha]_{1}^{2}, \\
Q_{L}=[Z]_{1}^{2}+M_{L}[\alpha]_{1}^{2},
\end{gathered}
$$

where $Z$ denotes a quantity that includes all energies that are independent of the amount of fluid in the calorimeter. Then,

or

$$
Q_{H}-Q_{L}=\left[M_{H}-M_{L}\right][\alpha]_{1}^{2}
$$

$$
\Delta \alpha=\Delta Q / \Delta M
$$

or

$$
\Delta \alpha / \Delta T=\Delta Q / \Delta T \Delta M .
$$

In other words, the change in the characteristic quantity, $\alpha$, in a given temperature interval is merely the difference in the heat required in the high and low filling experiments, divided by the difference in the mass of fluid in the calorimeter in the two experiments. 
It has also been shown [1] that the quantity $\alpha$ is related to the well known enthalpy, $H$, by the relation

where

$$
H=\alpha+\beta .
$$

$$
\beta=L v /\left(v^{\prime}-v\right)=T v d p / d T
$$

where $v^{\prime}$ and $v$ are the specific volumes of the saturated vapor and liquid, respectively, $L$ the heat of vaporization, $T$ the absolute temperature, and $d p / d T$ the vapor pressure slope. At the temperatures of the present experiments, the term $\beta$ is quite small compared to $\alpha$ so that the value of $\alpha$ is within a few parts in a thousand of the value of $H$. The value of $\Delta H / \Delta T$ for a given temperature interval is

$$
\Delta H / \Delta T=\Delta \alpha / \Delta T+\Delta \beta / \Delta T,
$$

and the value of $d H / d T$ along the saturation path is derived by applying a correction for curvature of the enthalpy function.

The calculation of $C_{\text {sat. }}$, the heat capacity of the liquid along the saturation path, from the values of $(d H / d T)_{\text {sat. }}$ is performed by using the fundamental definitions of $H$ and $C_{\text {sat }}$.

$$
\begin{gathered}
(d H / d T)_{\text {sat. }}=d E / d T+p d v / d T+v d p / d T, \\
C_{\text {sat. }}=(d Q / d T)_{\text {sat. }}=d E / d T+p d v / d T .
\end{gathered}
$$

\section{Hence}

$$
C_{\text {sat. }}=(d H / d T)_{\mathrm{sat} .}-v d p / d T=(d H / d T)_{\mathrm{sat}}-\beta / T .
$$

In the temperature and pressure range of these experiments, the values of $C_{\text {sat. }}$ are very close to the values of $C_{p}=1 \mathrm{~atm}$, probably within 0.2 percent. If desired, the value of $C_{p}$ may be calculated from the relation

$C_{p=1}=C_{\mathrm{sat}} .+\beta / T+T d^{2} v / d T^{2}(p-1)-d p / d T d H / d p$,

where $p$ is expressed in atmospheres. Accurate knowledge of specific volume is necessary in order to evaluate the factor $d^{2} v / d T^{2}$.

\section{Experimental Procedure}

The experimental procedure in the heat capacity experiments was very similar to that with the vaporization experiments. The sample in the calorimeter was brought to equilibrium at the desired starting temperature, and its temperature observed as noted in sections I and II. Measured electrical power was put into the calorimeter heater to heat the calorimeter at a rate of very close to $1 / 2$ deg per minute. At the same time, the power inputs to the envelope heaters, the throttle heater, and the reference block heater were carefully regulated. The reference block heater current was regulated manually, so that the reference block temperature was always very close to the calorimeter temperature. The throttle heater was regulated automatically, as in section I, so that the temperature of the throttle was high enough to prevent any part of the tube from becoming colder than the temperature of the vapor in the calorimeter. This precaution was necessary to avoid condensation in the tube. The envelope heaters were regulated as previously described, partly automatic and partly manual.

After the calorimeter had heated the desired amount (either 5 or 10 degrees), the calorimeter power was turned off and the calorimeter allowed to come to equilibrium, as indicated by thermoelements located on the calorimeter. Because of the effectiveness of the heat distributing system in the calorimeter, the time to come to equilibrium was only a few minutes. Usually about 10 minutes was allowed, which was considerably longer than necessary, judging from the thermoelement readings. The temperature of the calorimeter was then observed as before, and a new heating period started. Measurements of heat leak coefficients (envelope, throttle, and residual) were made as in section II, except that the residual heat leak was checked only at the beginning and end of a series of heat capacity measurements.

\section{Results of Heat-Capacity Experiments}

The results of the heat-capacity experiments are given in table 2. Column 2 gives the mass of fluid in the calorimeter in the experiments for the data listed. The corresponding heat of vaporization experiments in table 1 were made after the high-filling experiments and before the low-filling experiments. Column 3 indicates the type of heat function for which corresponding values are listed in columns 4 to 8 for the various temperature intervals covered by the experiments. For example, the low-filling experiments with $n$-heptane on Nov. 22, 1941 gave for the temperature interval $20^{\circ}$ to $25^{\circ} \mathrm{C}$, a value of $Q / \Delta T$ of 81.21 int. j/deg. 
TABLE 2. Results of heat-capacity experiments'

\begin{tabular}{|c|c|c|c|c|c|c|c|}
\hline \multirow{2}{*}{ Date } & \multirow{2}{*}{ Mass } & \multirow{2}{*}{ Heat function } & \multicolumn{5}{|c|}{ (Int. $\mathrm{j} / \mathrm{g}$ or int. $\mathrm{j} / \mathrm{g}-{ }^{\circ} \mathrm{C}$} \\
\hline & & & $10^{\circ}$ to $15^{\circ}$ & $15^{\circ}$ to $20^{\circ}$ & $20^{\circ}$ to $25^{\circ}$ & $25^{\circ}$ to $30^{\circ}$ & $30^{\circ}$ to $35^{\circ}$ \\
\hline \multicolumn{8}{|c|}{ WATER } \\
\hline $\begin{array}{l}11-7-41 \\
11-8-41 \\
11-12-41\end{array}$ & \begin{tabular}{c|}
$\vartheta$ \\
91.6182 \\
91.6182 \\
11.4744
\end{tabular} & $\begin{array}{l}\mathrm{Q} / \Delta T \\
\mathrm{Q} / \Delta T / \Delta T \\
{\left[\begin{array}{l}\Delta \alpha / \Delta T \text { (observed) } \\
\Delta \alpha / \Delta T(1939 \text {-calculated) } \\
\text { Observed-calculated }\end{array}\right.}\end{array}$ & $\begin{array}{r}451.65 \\
116.02 \\
4.1878 \\
4.1868 \\
+0.0010\end{array}$ & 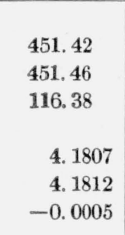 & $\begin{array}{r}451.36 \\
451.68 \\
116.68 \\
4.1780 \\
4.1775 \\
+0.0005\end{array}$ & $\begin{array}{r}451.45 \\
451.54 \\
117.03 \\
\\
4.1732 \\
4.1751 \\
-0.0019\end{array}$ & $\left.\begin{array}{r}451.59 \\
451.64 \\
117.20 \\
\\
4.1727 \\
4.1735 \\
-0.0008\end{array}\right]$ \\
\hline \multicolumn{8}{|c|}{$n$-HEPTANE } \\
\hline $\begin{array}{r}11-19-41 \\
\text { Do } \\
11-22-41 \\
11-24-41\end{array}$ & $\begin{array}{r}59.4754 \\
59.4754 \\
5.5453 \\
5.5453\end{array}$ & $\begin{array}{l}\mathrm{Q} / \Delta T \\
\mathrm{Q} / \Delta T \\
\mathrm{Q} / \Delta T \\
\mathrm{Q} / \Delta T \\
{\left[\begin{array}{l}\Delta \alpha / \Delta T \\
\Delta \beta / \Delta T\end{array}\right.} \\
\Delta H / \Delta T \\
C_{\text {sat. }} \text { (observed) } \\
C_{\text {sat. }}(1939 \text {-calculated) } \\
\text { Observed-calculated. }\end{array}$ & $\begin{array}{r}198.70 \\
198.66 \\
80.38 \\
80.32 \\
\\
2.1941 \\
0.0037 \\
2.1978 \\
2.1975 \\
2.1980 \\
-0.0005\end{array}$ & $\begin{array}{l}\text { 200. } 03 \\
\text { 200. } 03 \\
80.78 \\
80.74 \\
\text { 2. } 2116 \\
0.0046 \\
\text { 2. } 2162 \\
\text { 2. } 2159 \\
\text { 2. } 2160 \\
-0.0001\end{array}$ & $\begin{array}{r}\text { 201. } 38 \\
\text { 201. } 33 \\
81.21 \\
81.16 \\
\text { 2. } 2283 \\
0.0058 \\
2.2341 \\
2.2337 \\
2.2344 \\
-0.0007\end{array}$ & $\begin{array}{r}202.72 \\
202.69 \\
81.61 \\
81.61 \\
2.2454 \\
0.0068 \\
2.2522 \\
2.2517 \\
2.2531 \\
-0.0014\end{array}$ & $\begin{array}{r}204.10 \\
204.05 \\
82.05 \\
82.02 \\
\\
2.2631 \\
0.0081 \\
2.2712 \\
2.2706 \\
2.2721 \\
-0.0015\end{array}$ \\
\hline \multicolumn{8}{|c|}{ 2,2,4-TRIMETHYLPENTANE } \\
\hline $\begin{array}{r}12-4-41 \\
12-5-41 \\
12-9-41 \\
\quad \text { Do }\end{array}$ & $\begin{array}{r}61.1512 \\
61.1512 \\
61.1512 \\
7.4313 \\
7.4313\end{array}$ & $\begin{array}{l}Q / \Delta T \\
Q / \Delta T \\
Q / \Delta T \\
Q / \Delta T \\
Q / \Delta T \\
\\
\Delta \alpha / \Delta T \\
\Delta \beta / \Delta T \\
\Delta H / \Delta T \\
C_{\text {sat }} \text { (observed) } \\
C_{\text {sat }} \text {. (calculated) } \\
\text { Observed-calculated }\end{array}$ & $\begin{array}{r}192.27 \\
192.24 \\
192.25 \\
83.13 \\
83.21 \\
2.0307 \\
0.0038 \\
2.0345 \\
2.0342 \\
2.0341 \\
+0.0001\end{array}$ & $\begin{array}{r}193.81 \\
193.77 \\
193.79 \\
83.61 \\
83.64 \\
\\
\text { 2. } 0507 \\
0.0046 \\
2.0553 \\
2.0550 \\
2.0553 \\
-0.0003\end{array}$ & $\begin{array}{r}195.41 \\
195.37 \\
195.41 \\
84.05 \\
84.12 \\
2.0721 \\
0.0055 \\
2.0776 \\
2.0772 \\
2.0770 \\
+0.0002\end{array}$ & $\begin{array}{r}196.97 \\
196.95 \\
197.00 \\
84.51 \\
84.57 \\
2.0929 \\
0.0067 \\
2.0996 \\
2.0991 \\
2.0991 \\
0.0000\end{array}$ & $\begin{array}{c}198.58 \\
198.58 \\
198.65 \\
85.00 \\
85.03 \\
2.1144 \\
0.0079 \\
2.1223 \\
2.1217 \\
2.1217 \\
0.0000\end{array}$ \\
\hline \multicolumn{8}{|c|}{$n$-OCTANE } \\
\hline $\begin{array}{l}12-13-41 \\
12-15-41 \\
12-17-41 \\
12-18-41\end{array}$ & $\begin{array}{r}49.4233 \\
49.4233 \\
5.1301 \\
5,1301\end{array}$ & 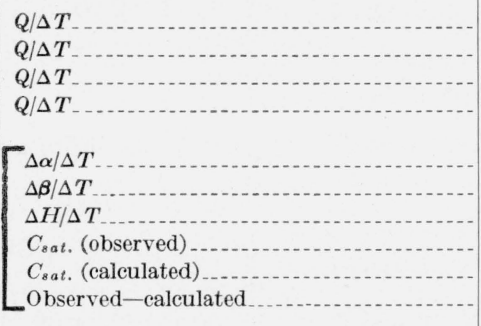 & $\begin{array}{r}175.57 \\
175.57 \\
79.06 \\
79.08 \\
\\
2.1787 \\
0.0013 \\
2.1800 \\
2.1799 \\
2.1804 \\
-0.0005\end{array}$ & 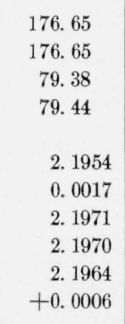 & $\begin{array}{r}\text { 177. } 74 \\
\text { 177. } 77 \\
\text { 79. } 76 \\
\text { 79. } \\
\text { 2. } 2124 \\
\text { 0. } 0021 \\
2.2145 \\
2.2144 \\
\text { 2. } 2134 \\
+0.0010\end{array}$ & 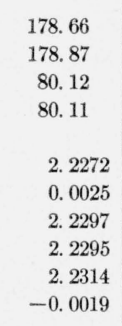 & $\begin{array}{r}180.05 \\
180.01 \\
80.47 \\
80.46 \\
\text { 2. } 2479 \\
0.0034 \\
2.2513 \\
2.2511 \\
2.2503 \\
+0.0008\end{array}$ \\
\hline \multicolumn{8}{|c|}{ 2-METHYLHEPTANE } \\
\hline $\begin{array}{r}12-23-41 \\
\text { Do } \\
1-3-42\end{array}$ & $\begin{array}{r}48.4561 \\
48.4561 \\
2.7255\end{array}$ & 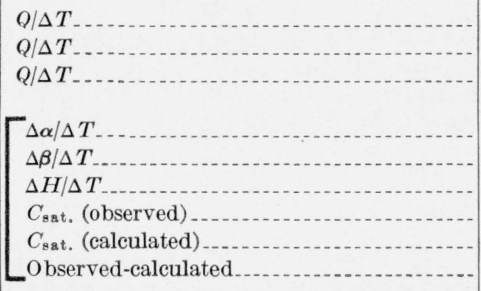 & $\begin{array}{r}171.97 \\
172.00 \\
73.58 \\
2.1518 \\
0.0018 \\
2.1536 \\
2.1535 \\
2.1536 \\
-0.0001\end{array}$ & $\begin{array}{r}173.15 \\
173.19 \\
73.90 \\
\\
2.1708 \\
0.0023 \\
2.1731 \\
2.1730 \\
2.1729 \\
+0.0001\end{array}$ & $\begin{array}{r}174.38 \\
174.38 \\
74.23 \\
\\
2.1900 \\
0.0029 \\
2.1929 \\
2.1927 \\
2.1923 \\
+0.0004\end{array}$ & $\begin{array}{r}175.51 \\
175.61 \\
74.60 \\
\\
2.2077 \\
0.0036 \\
2.2113 \\
2.2111 \\
2.2117 \\
-0.0006\end{array}$ & $\begin{array}{r}176.74 \\
176.82 \\
74.92 \\
\\
2.2274 \\
0.0043 \\
2.2317 \\
2.2314 \\
2.2312 \\
+0.0002\end{array}$ \\
\hline
\end{tabular}


TABLE 2. Results of heat-capacity experiments-Continued

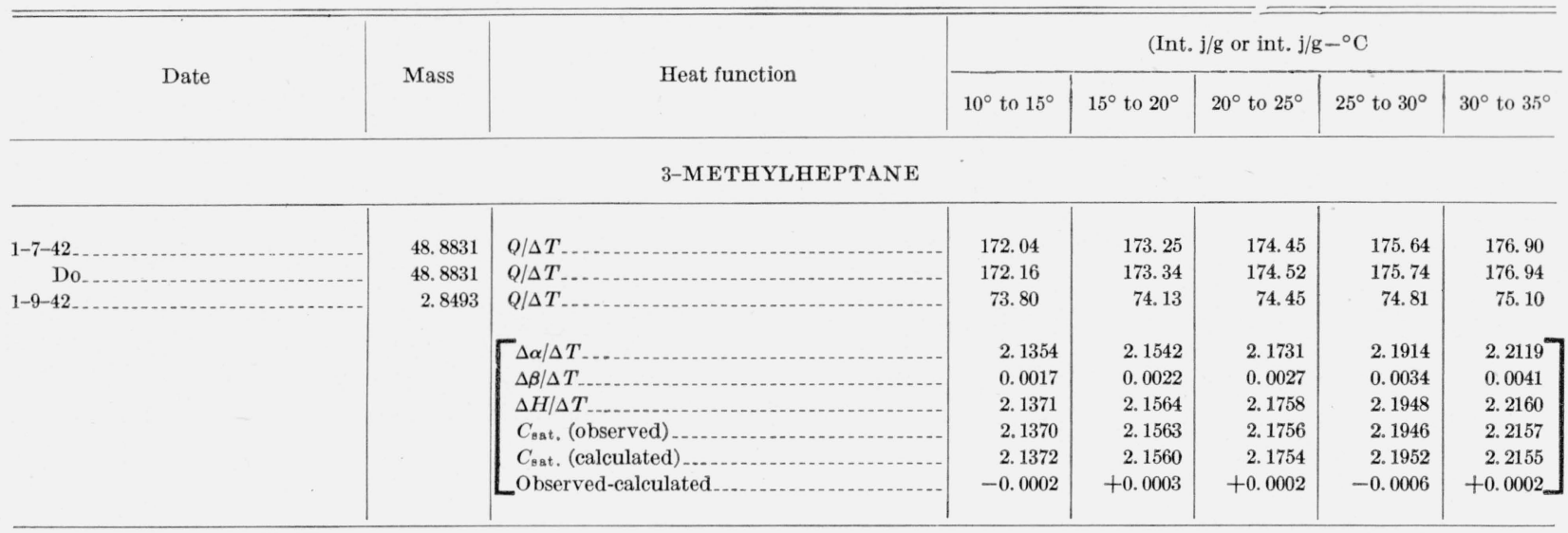

4-METHYLHEPTANE

\begin{tabular}{|c|c|c|c|c|c|c|}
\hline & & & $5^{\circ}$ to $15^{\circ} \mathrm{C}$ & $15^{\circ}$ to $25^{\circ} \mathrm{C}$ & $25^{\circ}$ to $30^{\circ} \mathrm{C}$ & $35^{\circ}$ to $45^{\circ} \mathrm{C}$ \\
\hline $1-13-42 \ldots \ldots \ldots$ & 49.0380 & $Q / \Delta T_{\ldots} \ldots$ & 172.02 & 174.72 & 177. 27 & 179.84 \\
\hline Do & 49.0380 & $Q / \Delta T$ & 172.26 & 174. 77 & 177.30 & 179.84 \\
\hline $1-15-42 \ldots$ & 2. 9001 & $Q / \Delta T$ & 73.90 & 74.57 & 75.24 & 75.90 \\
\hline & & $\Gamma \Delta \alpha / \Delta T$ & 2.1293 & 2. 1712 & 2. 2117 & $2.2528^{-m}$ \\
\hline & & $\Delta \beta / \Delta T_{\ldots}$ & 0.0033 & 0.0051 & 0.0078 & 0.0114 \\
\hline & & $\Delta H / \Delta T$ & 2. 1326 & 2. 1763 & 2. 2195 & 2. 2642 \\
\hline & & $C_{\text {sat. }}($ observed) & 2. 1325 & 2.1761 & 2. 2192 & 2. 2638 \\
\hline & & $C_{\text {sat. }}($ calculated) & 2. 1326 & 2. 1758 & 2. 2195 & 2. 2637 \\
\hline & & 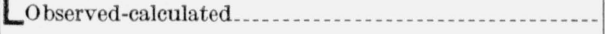 & -0.0001 & +0.0003 & -0.0003 & +0.0001 \\
\hline
\end{tabular}

2-5-DIMETHYLHEXANE

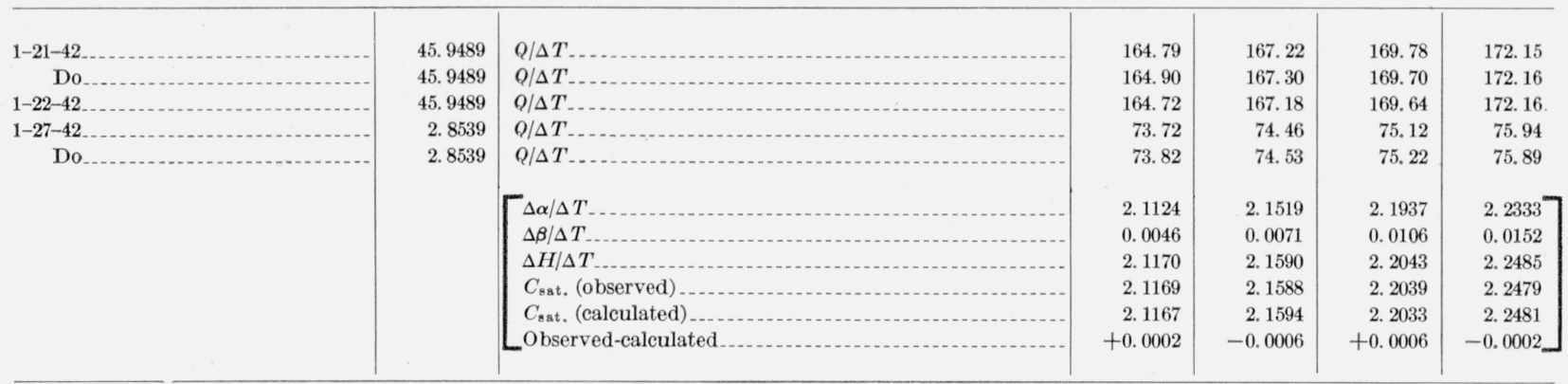

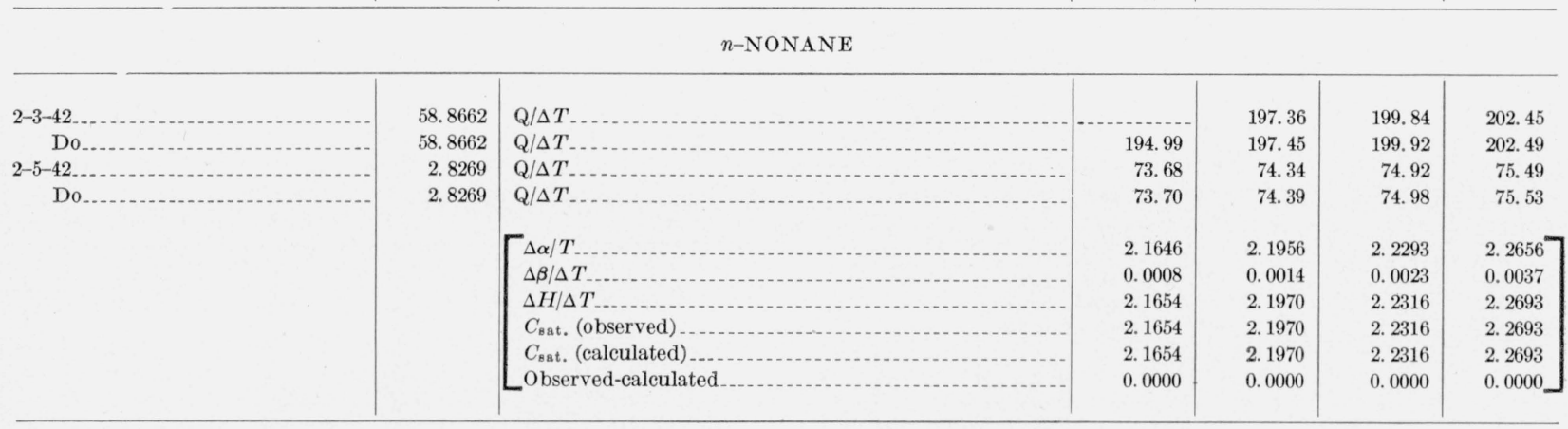


TABLE 2. Results of heat-capacity experiments-Continued

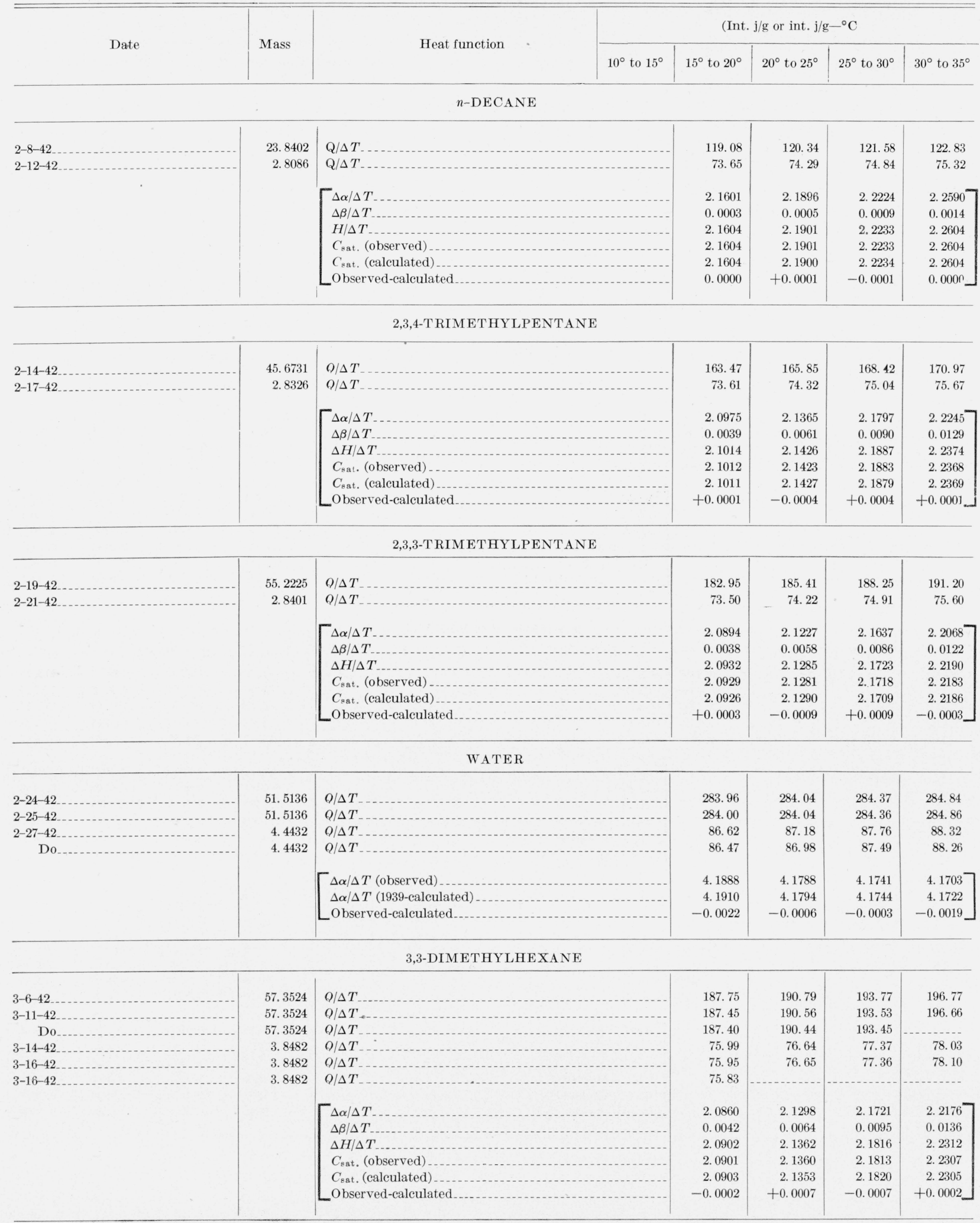


The values of $Q / \Delta T$ thus listed in table 2 are calculated from the electrical energy input during the experiment, corrected for the three heat leaks described in section II and for the departures of the beginning and end temperatures of the experiment from the desired even temperature. As in the vaporization experiments, the arithmetical sum of the heat leaks for an average experiment was about 1 or 2 joules, most of which was caused by regulating the temperature of the upper tube above the temperature of the calorimeter to avoid condensation. The heat leak on most experiments contributed only about 0.2 percent to the energy input, and even this small amount was effectively eliminated differentially by the experimental procedure that gave the same heat leak conditions in the high-filling experiments as in the low-filling experiments.

The beginning and end temperatures of the calorimeter in the heat capacity experiments were usually regulated to within a few hundredths of a degree of the desired even temperatures so that the resultant corrections applied to the measured $Q / \Delta T$ amounted to less than 1 percent. As the heat capacity of the calorimeter and contents is known from the experiments, these corrections should introduce no significant error in the results.

The values of $\Delta \alpha / \Delta T$ listed in table 2 are obtained by dividing the difference between the average values of $Q / \Delta T$ for the high-filling experiment and corresponding average values of $Q / \Delta T$ for the low-filling experiment, by $\Delta M$, the difference in the masses of fluid in the calorimeter in the high and low-filling experiments. Values of $\Delta H / \Delta T$ are calculated from $\Delta \alpha / \Delta T$ by adding $\Delta \beta / \Delta T$ calculated from specific volume and vapor pressure data as described under Method. Values of $C_{\text {sat. }}$ at the mid temperatures of the intervals are calculated from $\Delta H / \Delta T$ by first applying a curvature correction to get $d H / d T$ at the mid temperature of the intervals, and then subtracting values of $\beta / T$. All these corrections are small, so that the resulting values of $C_{\text {sat. }}$ do not differ from the $\Delta \alpha / \Delta T$ by more than a few parts per thousand.

In order to "smooth" the data, an equation of the form $C_{\text {sat. }}=A+B T+C T^{2}$ was fitted to the data for each material by the method of least squares. Table 3 gives the constants of the equation for the 12 hydrocarbons as well as values at 5 -degree intervals in the experimental range as calculated from these equations. The values of $C_{\text {sat. }}$ (calculated) listed in table 2 are also computed from these equations in order to judge the accidental variations in the experimental values of heat capacities. It was found that the average deviation of a determination of heat capacity from the value calculated from the equation was 0.011 percent for the 10-degree intervals and 0.022 percent for the 5-degree intervals.

Similar to the vaporization experiments, heat capacity experiments with water were made at the beginning of this series of measurements and near the end, as a check on the accuracy of the results. It was found that the 30 experiments with water gave an average difference of $\Delta \alpha / \Delta T$ of about 0.025 percent from the values reported with another calorimeter [4].

In addition to the check on the values of heat capacity of water, it was possible to also check on values of the heat capacity of $n$-heptane as determined in the same large calorimeter [4] as was used for water. These unpublished determina-

TABLE 3. Values of smoothed heat capacities

\begin{tabular}{|c|c|c|c|c|c|c|c|c|c|c|c|c|}
\hline \multirow{2}{*}{ Material } & \multicolumn{3}{|c|}{ Equation constants } & \multicolumn{9}{|c|}{$C_{\text {sat }}\left(\right.$ int. $\left.j / g^{-\circ} C\right)$} \\
\hline & $A$ & $10^{3} \mathrm{~B}$ & $10^{6} C$ & $5^{\circ}$ & $10^{\circ}$ & $15^{\circ}$ & $20^{\circ}$ & $25^{\circ}$ & $30^{\circ}$ & $35^{\circ}$ & $40^{\circ}$ & $45^{\circ}$ \\
\hline 2-methylheptane... & 2. 10547 & 3.840 & 0.853 & & 2. 1440 & 2. 1632 & 2. 1826 & 2. 2020 & 2. 2214 & 2. 2409 & & \\
\hline 3-methylheptane $\ldots \ldots \ldots$ & 2. 09208 & 3.490 & 9.425 & (n- & 2.1279 & 2. 1466 & 2. 1657 & 2. 1852 & 2. 2053 & 2. 2258 & & \\
\hline 4-methylheptane & 2.08990 & 4. 245 & 2. 500 & 2. 1112 & 2. 1326 & 2. 1541 & 2.1758 & 2. 1976 & 2. 2195 & 2. 2415 & 2. 2637 & 2. 2860 \\
\hline 2, 5-Dimethylhexane .......... & 2. 07498 & 4. 119 & 5. 248 & 2. 0957 & 2. 1167 & 2. 1379 & 2. 1594 & 2. 1812 & 2. 2033 & 2. 2256 & 2. 2481 & 2. 2710 \\
\hline 3, 3-Dimethylhexane & 2. 04712 & 4. 234 & 8. 750 & 2. 0685 & 2. 0903 & 2. 1126 & 2. 1353 & 2. 1584 & 2. 1820 & 2. 2060 & 2. 2305 & 2. 2554 \\
\hline $2,2,4$-Trimethylpentane $\ldots . .$. & 1. 98314 & 3.958 & 9. 419 & ............. & 2.0237 & 2.0425 & 2. 0661 & 2. 0880 & 2. 1104 & 2. 1332 & & \\
\hline $2,3,4$-Trimethylpentane & 2. 06320 & 3.603 & 18. 500 & 2. 0817 & 2. 1011 & 2.1214 & 2. 1427 & 2. 1648 & 2. 1879 & 2. 2120 & 2. 2369 & 22628 \\
\hline 2,3,3-Trimethylpentane ...... & 2. 06192 & 2. 786 & 28. 250 & 2. 0766 & 2. 0926 & 2. 1101 & 2.1290 & 2. 1492 & 2. 1709 & 2. 1941 & 2. 2186 & 2. 2445 \\
\hline$n$-Heptane & 2. 15453 & 3.396 & 6. 791 & 2.1717 & 2. 1892 & 2. 2070 & 2. 2252 & 2. 2437 & 2. 2625 & 2. 2817 & 2. 3012 & 2. 3211 \\
\hline$n$-Octane & 2. 14441 & 2.637 & 19.140 & - n & 2.1727 & 2. 1883 & 2. 2048 & 2. 2223 & 2. 2407 & 2. 2602 & & (n) \\
\hline$n$-Nonane & 2. 13688 & 2. 700 & 15. 250 & 2. 1508 & 2. 1654 & 2. 1808 & 2. 1970 & 2. 2139 & 2. 2316 & 2. 2501 & 2. 2693 & 2. 2893 \\
\hline$n$-Decane & 2. 13450 & 2. 407 & 18. 500 & 2. 1470 & 2. 1604 & 2. 1748 & 2. 1900 & 2. 2062 & 2. 2234 & 2. 2414 & 2. 2604 & 2. 2803 \\
\hline
\end{tabular}


tions were made in 1939 by Osborne, Stimson, and Ginnings with a sample of $n$-heptane furnished by D. B. Brooks of this Bureau. Three series of low-filling experiments were made over the temperature range $5^{\circ}$ to $100^{\circ} \mathrm{C}$, but only one series of high-filling experiments was completed in the range $5^{\circ}$ to $90^{\circ} \mathrm{C}$ on account of interruption of the experiments by a mechanical breakdown.

The results of the 1939 measurements on $n$-heptane are given in table 4 . Columns 2 and 3 give the net energy inputs for the low- and high-filling experiments, having 85.859 and $743.123 \mathrm{~g}$ of heptane, respectively. These values of net energy include heat leak correction and corrections for end temperatures. The values of $\Delta \alpha / \Delta T$ in column 4 were obtained by dividing the difference in net energies for the high and low fillings by the product of the difference in mass of heptane (657.264) times the number of degrees in the temperature interval. The values of $\beta / T$ in column 8 and $\Delta \beta / \Delta T$ in column 5 were calculated from liquid specific volume data in the International Critical Table [13] and vapor pressure data from the tables of the American Petroleum Institute Project 44 [14], and from Willingham et al. [16].

The values of $C_{\text {sat }}$. were calculated from $\Delta \alpha / \Delta T$

TABLE 4. Results of 1939 -heptane heat capacity experiments

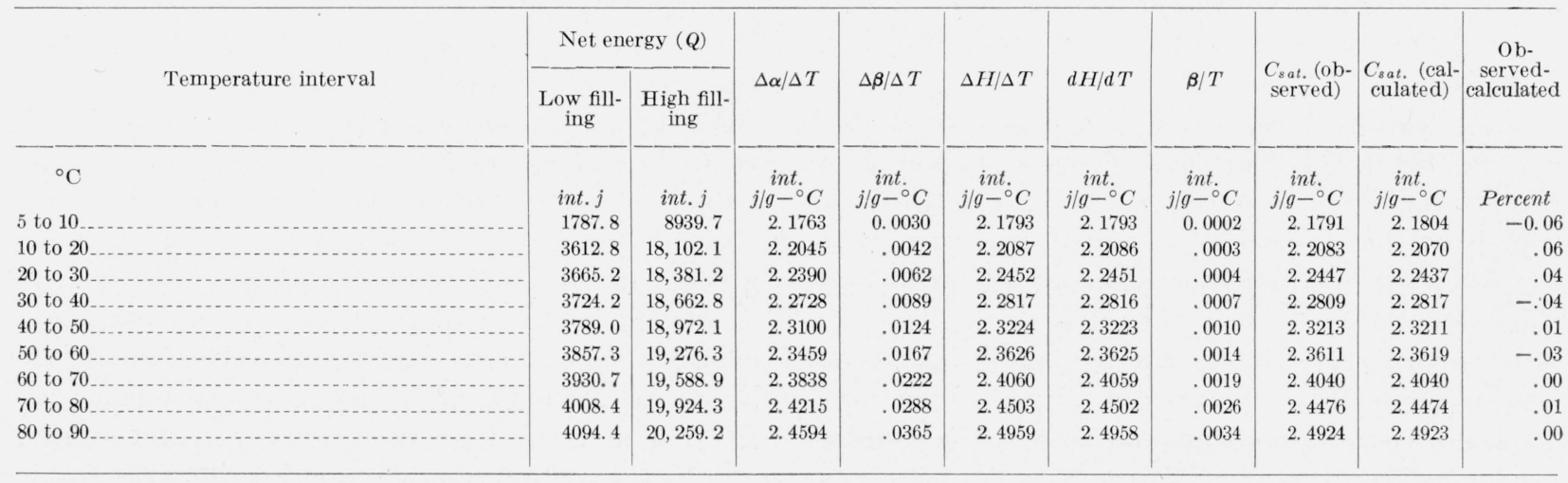

by the method used in table 2 . An equation of the type $C_{\text {sat. }}=A+B T+C^{2}$ was fitted to the observed values of $C_{\text {sat }}$. listed in table 4, giving values of the constants as $A=2.15453$, $B=.0033961$, and $C=6.7909 \times 10^{-6}$, when $T$ is in degrees $\mathrm{C}$ and $C_{\text {sat }}$, is in int. $\mathrm{j} / \mathrm{g}-\mathrm{deg} \mathrm{C}$. The average deviation of the 1939 observed values from the values calculated from this equation is 0.028 percent, whereas the average deviation of the 1941 observed values from this equation (based on the 1939 results) is 0.037 percent. A comparison of the observed values is given in figure 4.

\section{Discussion of Accuracy of Heat Capacity Results}

When the calorimeter was designed, it was not expected that it would give as accurate results in the heat capacity measurements as in the vaporization experiments. This was due to the small size of the calorimeter, which was a more important factor in the heat capacity experiments than

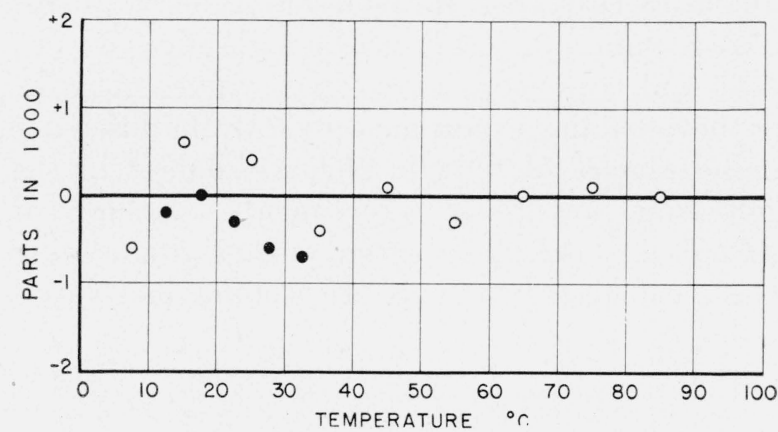

Figure 4. Deviations of observed heptane heat capacities from formulation.

O, 1939 observed; 1941 observed.

in the vaporization experiments. However, in view of the excellent agreement of the values of heat capacity of water and heptane with values obtained with a larger calorimeter at an earlier date, it is believed that the calorimeter is capable of better than 0.1 percent in heat capacities in spite of its small size. As some of the heat capacity results are based on scanty data, and some 
(such as $n$-decane) involve smaller amounts of hydrocarbon in the calorimeter than others, it is believed that the error in the heat capacity results is about 0.1 percent with most hydrocarbons such as $n$-heptane, but that it may be as large as 0.3 percent with a few hydrocarbons such as $n$-decane.

The authors acknowledge the participation of H. F. Stimson of this Bureau in the design of the calorimeter described in this paper. To him should go a large part of the credit for the design of a number of the important features of the calorimeter.

\section{References}

[1] N. S. Osborne, BS J. Research 4, 609 (1930).

[2] N. S. Osborne, H. F. Stimson, and E. F. Fiock, BS J. Research 5, 411 (1930).

[3] N. S. Osborne, H. F. Stimson, and D. C. Ginnings, J. Research NBS 18, 389 (1937).

[4] N. S. Osborne, H. F. Stimson, and D. C. Ginnings, J. Research NBS $\mathbf{2 3 ,} 197$ (1939).
[5] C. H. Meyers, BS J. Research 9, 807 (1932).

[6] E. F. Mueller, Bul. BS 13, 547 (1916) S288,

[7] A. F. Forziati, A. R. Glasgow, Jr., C. B. Willingham, and F. D. Rossini, J. Research NBS 36, 129 (1946) RP1695.

[8] F. L. Howard, T. W. Mears, A. Fookson, P. Pomerantz, and D. B. Brooks, J. Research NBS 38, 365 (1947).

[9] P. L. Cramer and M. J. Mulligan, J. Am. Chem. Soc. 58, 373 (1936).

[10] J. Timmermans and F. Martin, J. Chem. Phys. 23, 733 (1926).

[11] B. J. Mair and S. T. Schicktanz, J. Research NBS 11, 665 (1933).

[12] A. R. Glasgow, Jr., C. B. Willingham, and F. D. Rossini, National Bureau of Standards. Unpublished.

[13] Elizabeth W. Aldrich, Ind. and Eng. Chem. 3, 348 (1931).

[14] Tables of physical constants of selected hydrocarbons issued by the American Petroleum Institute Research Project 44.

[15] International Critical Tables 3 (McGraw-Hill Book Co., Inc., New York, N. Y., 1928).

[16] C. B. Willingham, W. J. Taylor, Joan M. Pignocco, and F. D. Rossini, J. Research NBS 35, 219 (1945).

Washington, May 14, 1947. 